\title{
Thermo-poro-mechanical analysis of landslides: from creeping behaviour to catastrophic failure
}

\author{
E. E. ALONSO* A. ZERVOS† and N. M. PINYOL ${ }^{*}+$
}

\begin{abstract}
The scope of the paper encompasses planar and compound sliding motions, which may exhibit creeping behaviour during a certain period but may evolve to a very rapid motion. Thermo-mechanical interactions, at the scale of the sliding surface, are accepted as a critical aspect to explain these motion phases and their relationship. The sliding kinetics and global equilibrium are described at a large scale and the evolving shearing strength at the sliding surface derives from the local analysis of the shearing band and its vicinity. Pore pressures, temperatures and related variables are calculated by resolving a set of balance equations. The paper describes the transition from creeping motions to a rapid event. Results are found in terms of dimensionless numbers. Calculation of the slide evolution requires special numerical techniques described in the paper. Band permeability is found to be the dominant property controlling the triggering of fast motions. The creeping stage and the eventual slide blow-up are intimately linked. This relationship is explored in the paper. The models presented can be readily used to back-analyse relevant case histories or, in principle, even to carry out predictive modelling, provided an adequate calibration is available for the material parameters.
\end{abstract}

KEYWORDS: creep; landslides; pore pressures; shear strength; strain localisation; temperature effects

\section{INTRODUCTION}

Large catastrophic landslides are a constant threat to human communities and infrastructure works. Their danger derives from the large volumes of rock mass they involve (well in excess of 1 million $\mathrm{m}^{3}$ ) and their high estimated sliding velocities $(10 \mathrm{~m} / \mathrm{s}$ to $100 \mathrm{~m} / \mathrm{s})$. Sosio et al. (2008) list a number of historical rock avalanches and their main characteristics. The known number of catastrophic landslides is, however, much larger and there is a continuous arrival of new cases, triggered by different natural and anthropogenic causes: earthquakes, heavy rain, reservoir impounding and rapid drawdown and excavations or river erosion. A wider view of catastrophic landslides at a regional scale and their interaction with other geodynamic processes is given by Hewitt et al. (2008). Active mountain formation and the associated ongoing crustal plate collisions indicate the natural occurrence of these events, which is not expected to decrease over time.

A classic landslide that has been extensively studied is that of Vaiont; Hendron \& Patton (1985), Müller (1964), Nonveiller (1987), Semenza (2001) and Paronuzzi et al. (2013) provide detailed and informative contributions. Other large-scale catastrophic landslides associated with reservoir operations have been reported by Alcántara-Ayala \& Domínguez-Morales (2008) (San Juan de Grijalva slide in Mexico, 2007); Wang et al. (2004) and Dai et al. (2004) (Qiangjianping slide in China, towards the reservoir of the Three Gorges Project, 2003); Chamot (1993), Plaza-Netos \& Zevallos (1994), Schuster et al. (2002) and Harden (2004) (La Josefina landslide, Ecuador, in 1993). An often reported

Manuscript received 20 March 2015; revised manuscript accepted 25 June 2015. Published online ahead of print 11 August 2015.

Discussion on this paper closes on 1 August 2016, for further details see p. ii.

* Department of Geotechnical Engineering and Geosciences, Universitat Politecnica de Catalunya (UPC), Barcelona, Spain.

$\dagger$ Faculty of Engineering and the Environment, University of Southampton, Southampton, UK.

* Centre Internacional de Metodes Numerics en Enginyeria, Universitat Politecnica de Catalunya (UPC), Barcelona, Spain. case in recent years is the giant Tsaoling landslide, Taiwan, that was triggered by the 1999 Chi-Chi earthquake (Chen et al., 2003; Tang et al., 2009; Liao et al., 2011; Wu \& Chen, 2011; Yang et al., 2014.) In general, the interpretation of earthquake-induced motion requires velocity- and, in some cases, displacement-dependent shear strength weakening of the failure surface. This 'slip weakening' effect is discussed below because of its attributed relevance to the sudden acceleration of rapid slides.

The morphology and dynamics of these events is quite diverse. Hungr et al. (2014) provide an updated classification of landslides but, for the purpose of this paper, flow-like motions may be broadly distinguished from motions with a dominant sliding mode of deformation. This distinction is relevant when considering the mathematical methods of analysis available. In the first case hydrodynamic motion equations and soil/rock properties often associated with the concept of viscosity have been developed (Iverson et al., 1997; Cascini et al., 2010; Pastor et al., 2014). In the second case attention is concentrated on the position and frictional characteristics of the sliding surfaces, which should satisfy conditions of kinematic compatibility. This is the approach followed here. Further, a large number of numerical modelling techniques exist, which are capable of simulating landslide initiation and motion. Methods for the analysis of continua such as the finite-element method (FEM) or the material point method (MPM) (Duncan, 1996; Więckowski et al., 1999; Darve \& Laouafa, 2000; Bardenhagen \& Kober, 2004; Andersen \& Andersen, 2010; Conte et al., 2010; Pinyol et al., 2011; Zabala \& Alonso, 2011; Alonso et al., 2014; Yerro et al., 2014) may describe the deforming mass by elastoplastic constitutive equations familiar in soil mechanics. The discrete-element method (DEM) and related procedures describe the moving mass by laws of interaction between particles or blocks (Cleary \& Campbell, 1993; Campbell et al., 1995).

If the main deformation mechanism considered is one of sliding along localised and thin shearing surfaces, the underlying assumption is that these surfaces are already fully developed. Of the four different types of slope movements 
described by Leroueil (2001), it is the post-failure stage following first-time failures that is of concern; this includes the movement of the sliding mass from immediately after the full development of the shearing surface until it comes to rest, as well as reactivated slides, where movement restarts along a pre-existing failure surface developed during a past event. It is physical and physicochemical processes occurring at these shearing surfaces that determine the slide's motion and its evolution in time. However, the enormous difference of scale between the thickness of the shearing band and that of the slide raises difficulties. Integration of both scales in a common calculation procedure requires a trade-off, as methods providing a reasonable description of the entire moving mass are ill-conditioned to describe complex physical mechanisms at the scale of a shearing band. However, a combination of simple dynamic equilibrium models for the entire slide and closer attention to the deforming shearing bands proves useful. This is the approach followed here, in line with Voight \& Faust (1982), Hendron \& Patton (1985), Vardoulakis (2002), Veveakis et al. (2007), Pinyol \& Alonso (2010a, 2010b), Goren \& Aharonov (2009), Cecinato et al. (2011), Cecinato \& Zervos (2012). In all these cases the heat generated by friction and the resulting pressurisation of interstitial water were fundamental parts of the analysis; their relevance in explaining high landslide velocities was first highlighted in the pioneering contributions of Habib (1975), Uriel Romero \& Molina (1977), Goguel (1978) and Voight \& Faust (1982). Table 1 summarises the main aspects of published contributions on thermal effects and rapid landslide triggering.

The scope of the paper is limited to landslides whose evolving geometry is characterised by soil or rock masses that essentially maintain their original bulk stiffness and strength. The motion is explained by localised shearing surfaces such as those often located in clayey strata described as indurated claystones or overconsolidated clays. Interestingly, Tang et al. (2009) observe that, despite the heavy internal fracturing observed in many large landslides, they show a 'remarkable tendency to remain in a more or less unchanged sequential order'; this helps extend the analysis described here to a larger class of landslides.

From a geotechnical perspective, it is important to distinguish between first-time failures and reactivation of ancient landslides. The first type develops in 'intact' sites. They are difficult to analyse, especially when brittle materials are involved in the vicinity of the potential failure surface, as is the case of hard soils or soft argillaceous rocks, in particular those of high plasticity. The strength operating in practice and the geometry of the failure surface are difficult to predict because the failure mechanism develops progressively. Early classic studies on this topic were published by Skempton et al. (1967), Bjerrum (1967) and Bishop (1967, 1971). More recent contributions include those by Cooper (1996), Potts et al. (1990), Dounias et al. (1996), Mesri \& Shahien (2003), Gens \& Alonso (2006) and Zabala \& Alonso (2011).

In contrast, re-activated ancient landslides occur on a pre-existing sliding surface that has been subjected to an increasing history of accumulated relative displacements. Hence, it is expected that cohesion will be insignificant on the sliding surface and the friction angle will be close or equal to residual values. It is widely accepted that ancient landslides exhibit a low safety factor (SF) close to conditions of strict equilibrium $(S F=1)$. Icold $(2002)$ reports that in at least $75 \%$ of cases where old landslides (active or inactive) are disturbed, for example, by an excavation or by submerging the toe, slide reactivation or an increase in velocity is observed. It is also frequently observed, especially in consolidated clayey strata, that a very low value of friction angle, even lower than the residual friction determined in ring shearing tests, operates in joints and shearing zones of ancient landslides. The evolution of residual strength during resting times is a controversial subject which has been discussed in Alonso \& Pinyol (2014).

Consider, as an introduction to the remainder of the paper, the motion of a block sliding on a friction-resistant surface inclined at angle $\beta$. Velocity increases linearly with time, $t$, following the equation

$$
v=g \sin \beta(1-\mathrm{SF}) t
$$

where $g$ is the modulus of the gravity acceleration and SF is the initial safety factor, defined as the ratio between resisting (shear strength) and disturbing shear stress. If $\mathrm{SF}=1 \cdot 0$, the block remains still. To initiate motion it is necessary to introduce some imbalance between resisting and disturbing stress. In real situations involving re-activated slides the imbalance may have different origins but it is typically small; for example, raising the water level in a reservoir slowly affects pore pressures in the valley upstream.

For $\mathrm{SF}=0.99$ and $\beta=10^{\circ}$, equation (1) predicts that a catastrophic sliding velocity of $1 \mathrm{~m} / \mathrm{s}$ will be reached in $58 \mathrm{~s}$. However, field evidence does not support this result. A reasonable explanation is that the friction angle increases slightly as slide motion causes the rate of shearing on the failure plane to increase. Then $S F$ increases to $S F=1$ and the slide reaches dynamic equilibrium and exhibits creeping motion; that is, it moves with constant or near-constant velocity that is also relatively low.

Experience also indicates (this is the case of Vaiont) that a relatively slow creep motion of a few $\mathrm{mm}$ /day may evolve to $30 \mathrm{~m} / \mathrm{s}$ in $15 \mathrm{~s}$. However, equation (1) predicts, for the same slope angle, that for a small reduction of SF by $1 \%$ it takes $30 \mathrm{~min}$ to reach $30 \mathrm{~m} / \mathrm{s}$. Therefore equation (1) is unable to explain observations at the two scales of the motion of interest in practice: the creeping states and the eventual catastrophic outcome.

Material brittleness may explain a significant reduction of shear strength at the start of the motion. It may be invoked in cases of first-time failures but it cannot be easily justified in reactivated slides or in creeping motions that may evolve into a rapid slide. It may be also present in compound sliding motions which require shearing across 'intact' rock and not only on the basal sliding surface. This is certainly an acceptable scenario in some cases but it cannot explain the rapid motion of planar slides, which is a common case.

This paper is organised as follows: the question of the strain rate dependence of friction is discussed in the section 'Strain-rate-dependent friction and precursory sliding motions'. In the section entitled 'A THM strain-ratedependent sliding block model. Problem formulation', a thermo-hydro-mechanical (THM) model for an infinite planar slide is presented, using appropriate dimensionless variables. The section 'Numerical integration' discusses the numerical methods developed to solve the corresponding initial/boundary value problem, and the section 'Analysis' contains a range of numerical results that provide insights into the underlying phenomena. Some conclusions are presented in the final section 'Conclusions'.

\section{STRAIN-RATE-DEPENDENT FRICTION AND PRECURSORY SLIDING MOTIONS}

Before discussing some results of shearing experiments it is convenient to briefly examine some basic concepts of the theoretical understanding of friction. The initial contributions are presented in Bowden \& Tabor (1964). Mitchell (1976) and Rice (2001) describe how employing the theory of 'activation 
Table 1. Contributions to thermal analysis of catastrophic landslides

\begin{tabular}{|c|c|c|c|c|c|}
\hline References & $\begin{array}{l}\text { Problem description and governing } \\
\text { equations }\end{array}$ & Sliding geometry & Constitutive modelling & $\begin{array}{l}\text { Case analysed and particular } \\
\text { characteristics }\end{array}$ & Main emphasis \\
\hline Habib (1967) & $\begin{array}{l}\text { Heat induced by friction on a shear } \\
\text { band, including heat losses }\end{array}$ & Planar & N/A & & $\begin{array}{l}\text { Generated vapour pressure in the } \\
\text { shearing band may explain a rapid } \\
\text { motion }\end{array}$ \\
\hline $\begin{array}{l}\text { Uriel Romero \& } \\
\text { Molina (1977) }\end{array}$ & $\begin{array}{l}\text { Dynamics of motion expressed as a } \\
\text { balance of energy: slide } \\
\text { deformation, basal friction, impulse } \\
\text { of reservoir water and kinetic } \\
\text { energy. Pore pressure determined in } \\
\text { a phase diagram vapour-liquid } \\
\text { water }\end{array}$ & $\begin{array}{r}\text { Compound failure } \\
\text { surface. Defined } \\
\text { by vertical slices }\end{array}$ & Mohr-Coulomb & $\begin{array}{l}\text { Vaiont. Run-out and velocity } \\
\text { determined during the entire } \\
\text { motion }\end{array}$ & Explaining the high velocity of Vaiont \\
\hline $\begin{array}{l}\text { Voight \& Faust } \\
\quad \text { (1982) }\end{array}$ & $\begin{array}{l}\text { Rigid mass sliding and deformation } \\
\text { concentration in a shear band } \\
\text { Saturated shear band } \\
\text { Terzaghi's effective stress } \\
\text { Mass, energy and momentum } \\
\text { balances } \\
\text { One-dimensional model for heat } \\
\text { and pore water pressure dissipation }\end{array}$ & Planar & Mohr-Coulomb & $\begin{array}{l}\text { Vaiont. Average block. 1D } \\
\text { finite-element analysis }\end{array}$ & $\begin{array}{l}\text { Heat-induced fluid pressure explains } \\
\text { Vaiont velocity }\end{array}$ \\
\hline $\begin{array}{l}\text { Vardoulakis (2000, } \\
\text { 2002) }\end{array}$ & $\begin{array}{l}\text { As in Voight \& Faust (1982). } \\
\text { Numerical analysis. } \\
\text { Heat advective term negligible. } \\
\text { No vapour generation }\end{array}$ & Slip circle & $\begin{array}{l}\text { Mohr-Coulomb frictional } \\
\text { strength } \\
\text { Shear strain and shear strain } \\
\text { rate softening of frictional } \\
\text { coefficient. } \\
\text { Thermal expansion } \\
\text { coefficient of the soil skeleton } \\
\text { including thermoelastic } \\
\text { expansion and thermoplastic } \\
\text { collapse }\end{array}$ & $\begin{array}{l}\text { Vaiont. } \\
\text { Slide triggering by reducing the } \\
\text { frictional angle from the strict } \\
\text { equilibrium }\end{array}$ & Dynamic post failure response \\
\hline $\begin{array}{l}\text { Veveakis et al. } \\
\quad(2007)\end{array}$ & $\begin{array}{l}\text { As in Voight \& Faust (1982). } \\
\text { Analytical solutions }\end{array}$ & Planar & $\begin{array}{l}\text { Mohr-Coulomb frictional } \\
\text { strength. } \\
\text { Thermal softening and } \\
\text { velocity strengthening law for } \\
\text { frictional coefficient. } \\
\text { Thermal expansion } \\
\text { coefficient of the soil skeleton } \\
\text { including thermoelastic } \\
\text { expansion and thermoplastic } \\
\text { collapse }\end{array}$ & $\begin{array}{l}\text { Vaiont. } \\
\text { Slide triggering by reducing } \\
\text { frictional angle from strict } \\
\text { equilibrium } \\
\text { Constant water table in Veveakis } \\
\text { et al. }(2007)\end{array}$ & $\begin{array}{l}\text { Long creeping phase of Vaiont } \\
\text { landslide and the final high } \\
\text { acceleration due to the onset of } \\
\text { thermal pressurisation }\end{array}$ \\
\hline $\begin{array}{l}\text { Goren \& Aharonov } \\
\text { (2007) }\end{array}$ & $\begin{array}{l}\text { As in Voight \& Faust (1982). } \\
\text { Numerical analysis. } \\
\text { Advective term and heat } \\
\text { conduction negligible. } \\
\text { No vapour generation }\end{array}$ & Planar & $\begin{array}{l}\text { Mohr-Coulomb frictional } \\
\text { strength. } \\
\text { Constant frictional } \\
\text { coefficient }\end{array}$ & $\begin{array}{l}\text { Synthetic cases. } \\
\text { Slide triggering by an initial } \\
\text { velocity. } \\
\text { Sensitivity analysis }\end{array}$ & $\begin{array}{l}\text { Long travel distances of landslides } \\
\text { and their relation to slide volumes } \\
\text { depending on the depth-dependent } \\
\text { permeability }\end{array}$ \\
\hline
\end{tabular}




\begin{tabular}{|c|c|c|c|c|c|}
\hline References & $\begin{array}{l}\text { Problem description and governing } \\
\text { equations }\end{array}$ & Sliding geometry & Constitutive modelling & $\begin{array}{l}\text { Case analysed and particular } \\
\text { characteristics }\end{array}$ & Main emphasis \\
\hline $\begin{array}{l}\text { Goren \& Aharonov } \\
\text { (2009) }\end{array}$ & $\begin{array}{l}\text { As in Voight \& Faust (1982). } \\
\text { Numerical analysis. } \\
\text { Advective term and heat } \\
\text { conduction negligible. } \\
\text { No vapour generation }\end{array}$ & Planar & $\begin{array}{l}\text { Mohr-Coulomb frictional } \\
\text { strength. } \\
\text { Constant frictional } \\
\text { coefficient. } \\
\text { Constant thermal expansion } \\
\text { coefficient }\end{array}$ & $\begin{array}{l}\text { Synthetic cases. } \\
\text { Slide triggering by imposing an } \\
\text { initial velocity (e.g. simulating an } \\
\text { earthquake) and imposing an } \\
\text { excess pore water pressure that } \\
\text { dissipates in time (e.g. simulating } \\
\text { rain of snow melt infiltration) }\end{array}$ & $\begin{array}{l}\text { Sensitivity analysis of the triggering } \\
\text { factors and constitutive and } \\
\text { geometrical parameters to evaluate } \\
\text { the effect on the regime of the } \\
\text { landslide, which may become an } \\
\text { arrested or catastrophic slide }\end{array}$ \\
\hline $\begin{array}{l}\text { Pinyol \& Alonso } \\
\text { (2010a) }\end{array}$ & $\begin{array}{l}\text { As in Voight \& Faust (1982). } \\
\text { Analytical solution. } \\
\text { Advective term and heat } \\
\text { conduction negligible. } \\
\text { Incompressible water and soil } \\
\text { skeleton. } \\
\text { No vapour generation }\end{array}$ & Planar & $\begin{array}{l}\text { Mohr-Coulomb frictional } \\
\text { strength. } \\
\text { Constant frictional } \\
\text { coefficient. } \\
\text { Constant thermal expansion } \\
\text { coefficient }\end{array}$ & $\begin{array}{l}\text { Synthetic cases. } \\
\text { Slide triggering by increasing the } \\
\text { water level }\end{array}$ & $\begin{array}{l}\text { Analytical solution for the slide } \\
\text { velocity. } \\
\text { Sensitivity analysis of constitutive } \\
\text { and geometrical parameters to } \\
\text { evaluate the slide evolution }\end{array}$ \\
\hline $\begin{array}{l}\text { Pinyol \& Alonso } \\
\quad(2010 \mathrm{~b})\end{array}$ & $\begin{array}{l}\text { As in Voight \& Faust (1982). } \\
\text { Numerical analysis. } \\
\text { Advective term and heat } \\
\text { conduction negligible. } \\
\text { No vapour generation }\end{array}$ & $\begin{array}{l}\text { Compound failure } \\
\text { surface. Two } \\
\text { interacting } \\
\text { wedges describe } \\
\text { evolving } \\
\text { geometry }\end{array}$ & $\begin{array}{l}\text { Mohr-Coulomb frictional } \\
\text { strength. } \\
\text { Constant frictional } \\
\text { coefficient. } \\
\text { Constant thermal expansion } \\
\text { coefficient }\end{array}$ & $\begin{array}{l}\text { Vaoint. } \\
\text { Slide triggering by increasing the } \\
\text { water reservoir level from the } \\
\text { strict equilibrium }\end{array}$ & $\begin{array}{l}\text { Dynamic post failure response. } \\
\text { Sensitivity analysis of constitutive } \\
\text { parameters and scale effects }\end{array}$ \\
\hline Goren et al. (2010) & $\begin{array}{l}\text { As in Voight \& Faust (1982). } \\
\text { Numerical analysis. } \\
\text { Advective term and heat } \\
\text { conduction negligible. } \\
\text { No vapour generation }\end{array}$ & $\begin{array}{l}\text { Planar sliding } \\
\text { travelling along } \\
\text { a surface not } \\
\text { totally planar }\end{array}$ & $\begin{array}{l}\text { Mohr-Coulomb frictional } \\
\text { strength. } \\
\text { Constant frictional } \\
\text { coefficient. } \\
\text { Constant thermal expansion } \\
\text { coefficient. } \\
\text { Thermal decomposition of } \\
\text { Dolomite which involve } \\
\text { increments in porosity. } \\
\text { Non-constant permeability }\end{array}$ & $\begin{array}{l}\text { The Heart Mountain landslide in } \\
\text { Canada }\end{array}$ & $\begin{array}{l}\text { Simulation of the long runout features } \\
\text { of the simulated landslides }\end{array}$ \\
\hline $\begin{array}{l}\text { Cecinato et al. } \\
\text { (2011), } \\
\text { Cecinato \& } \\
\text { Zervos (2012) }\end{array}$ & $\begin{array}{l}\text { As in Voight \& Faust (1982). } \\
\text { Numerical analysis. } \\
\text { Heat advective term negligible }\end{array}$ & $\begin{array}{l}\text { Planar and slip } \\
\text { circle }\end{array}$ & $\begin{array}{l}\text { Thermoplastic modified Cam } \\
\text { Clay. } \\
\text { Strain, strain rate and } \\
\text { temperature softening of the } \\
\text { critical state parameter } \\
\text { function of the friction angle } \\
\text { at critical states. } \\
\text { Thermal expansion } \\
\text { coefficient of the soil skeleton } \\
\text { including thermoelastic } \\
\text { expansion and thermoplastic } \\
\text { collapse }\end{array}$ & $\begin{array}{l}\text { Vaiont in Cecinato et al. (2011). } \\
\text { Jiufenghershan landslide } \\
\text { (Taiwan) in Cecinato \& Zervos } \\
\text { (2012) }\end{array}$ & $\begin{array}{l}\text { Evaluation of the effect of the } \\
\text { thermal, strain and strain rate } \\
\text { softening and the pressurisation } \\
\text { mechanism in Cecinato et al. } \\
\text { (2011). } \\
\text { Parametric analysis in Cecinato } \\
\text { \& Zervos (2012) }\end{array}$ \\
\hline He et al. (2015) & $\begin{array}{l}\text { As in Voight \& Faust (1982). } \\
\text { Numerical analysis. } \\
\text { Advective term and heat } \\
\text { conduction negligible. } \\
\text { Depth-average integration model }\end{array}$ & Planar & $\begin{array}{l}\text { Mohr-Coulomb frictional } \\
\text { strength. } \\
\text { Constant frictional } \\
\text { coefficient. } \\
\text { Constant thermal expansion } \\
\text { coefficient }\end{array}$ & Synthetic case & $\begin{array}{l}\text { A depth-averaged model coupled with } \\
\text { a thermo-poro-elastic approach in } \\
\text { the shear zone }\end{array}$ \\
\hline
\end{tabular}


energy' at the level of microscopic contacts leads to the common law of friction. A frictional contact is idealised as a number of isolated contact points (Fig. 1) where adhesion $\left(\tau_{\mathrm{c}}\right)$ and normal stresses $\left(\sigma_{\mathrm{c}}\right)$ are understood to act at the scale of molecular interactions between the minerals in contact. Normal and shear stresses are expected to reach high local values and are controlled by chemical reactions. Using equilibrium, the macroscopic shear and normal stresses ( $\tau$ and $\sigma$ ) are related to their microscopic counterparts as

$$
\tau=\sigma \frac{\tau_{\mathrm{c}}}{\sigma_{\mathrm{c}}}
$$

which justifies why shear stress is linearly related to normal stress.

However, under transient shearing, chemical reactions at the molecular scale of the isolated process zones of the local contacts are expected to change the value of the adhesion stresses $\left(\tau_{\mathrm{c}}\right)$. If local chemical reactions follow a rate process, their velocity of reaction can be written

$$
v=v_{1} \exp \left(-\frac{E}{R T}\right)
$$

where $E$ is the activation energy, $T$ is the absolute temperature, $R$ is the gas constant and $v_{1}$ is a reference shearing rate. The interpretation of this equation is that the energy $E$ in equation (3) allows a shearing rate velocity $v$. $E$ has the meaning of a threshold energy barrier: if it decreases, velocity increases. Applied stresses decrease the energy barrier and increase the velocity of the processes taking place at the point contacts and, therefore, the velocity of deformation. Stress is understood as energy per unit volume, so the effect of stress on the energy barrier $E$ can be expressed as

$$
E=E_{1}-\tau_{\mathrm{c}} \Omega
$$

where $\Omega$ is an active volume of contact bonds and $E_{1}$ is a reference energy barrier. Equations (3) and (4) lead to

$$
\tau=\sigma\left[\frac{E_{1}}{\Omega \sigma_{\mathrm{c}}}+\frac{R T}{\Omega \sigma_{\mathrm{c}}} \ln \frac{v}{v_{1}}\right]
$$

which predicts a linear increase of friction with the logarithm of shearing velocity. The reference term $E_{1} /\left(\Omega \sigma_{\mathrm{c}}\right)$ is interpreted as a basic friction, which may depend on the state of the frictional surface; 'state' may include shearing relative displacement, applied stress and time (Rice et al., 2001). The friction law may then be written

$$
\frac{\tau}{\sigma}=f=f^{*}+\bar{\psi}+A \ln \frac{v}{v^{*}}
$$

where $f^{*}$ is a basic friction and $\bar{\psi}$ includes effects other than those associated with shearing velocity.

Experimental results at low shearing rates tend to support equation (6). For instance, based on direct and ring shear tests of highly plastic clay layers of the Clearwater formation in Alberta, Canada, Wedage et al. (1998) propose the following empirical relationship between residual friction

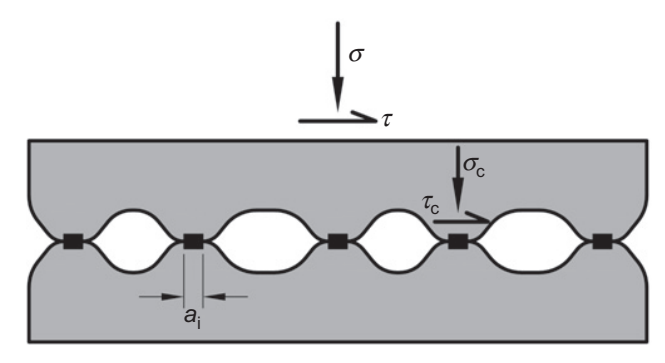

Fig. 1. Sketch to illustrate the concept of friction and shearing rate

$$
\tan \phi=\tan \phi_{0}\left(1+a \ln \frac{\dot{\varepsilon}}{\dot{\varepsilon_{0}}}\right)
$$

Cooper et al. (1998) investigated the effect of rate of shear on ring shear tests performed on high-plasticity Gault clay. Shearing rates varied almost four orders of magnitude, from $0.5 \mathrm{~mm} / \mathrm{min}$ to $0.0001 \mathrm{~mm} / \mathrm{min}$, but still within the range expected in creeping slide motions. Tika et al. (1996) extended the rate of shearing to the range $10^{-5}-10^{4} \mathrm{~mm} / \mathrm{min}$ and concluded that the evolution of residual strength depends on the type of soil. They found that some soils exhibit a 'negative' rate effect of the residual strength, which was explained as the result of an increase in water content in the shear zone, because of the dilatant effect of 'turbulent' shearing (which requires some granular content). Skempton (1985) presented results of ring shear test on clays conducted at rates from 100 times faster to 100 times slower than the commonly used $0.01 \mathrm{~mm} / \mathrm{min}$; they showed that the residual strength increased by about $2.5 \%$ per $\log$ cycle increase in strain rate, an increase that Skempton (1985) acknowledges can cause large changes in the rate of movement.

Direct shear tests on polished surfaces of rock (Dieterich, 1979; Ruina, 1983) support a linear increase of the friction coefficient with the logarithm of the shearing rate. Alternative proposals have also been presented, for example, Davis et al. (1993) propose

$$
\frac{\tau}{\sigma}=f=f^{*}+b \frac{v}{v_{\mathrm{r}}} \exp \left(\frac{-v}{v_{\mathrm{r}}}\right)
$$

The velocity term in equation (8) provides an initial increase in friction with velocity followed by a decrease for $v>v_{\mathrm{r}}$.

Testing devices capable of shearing soil samples to velocities in excess of $0 \cdot 1 \mathrm{~m} / \mathrm{s}$ have been developed in the past decade. Temperature in these tests rises to values that can cause transformation of minerals. As a rough guide, montmorillonite loses water molecules from interlayers at temperatures $<200^{\circ} \mathrm{C}$; kaolinite loses water and transforms into a complex amorphous structure of aluminum and silica compounds at about $550^{\circ} \mathrm{C}$ and calcite transforms into calcium oxide $(\mathrm{CaO})$ and releases carbon dioxide $\left(\mathrm{CO}_{2}\right)$ gas at temperatures of $600-850^{\circ} \mathrm{C}$.

Ujiie \& Tsutsumi (2010) report the results of tests performed on clayey gouges in a rotary shear apparatus capable of measuring the shear-band temperature. In saturated samples, temperature increase and reduction of apparent friction under high shearing velocity (in excess of $0 \cdot 1 \mathrm{~mm} / \mathrm{s}$ ) develop in tandem. The authors attributed the loss of friction to the thermally induced dilation of water and concluded that mineral de-hydration and water vaporisation were not responsible for the rapid 'slip weakening' observed. For shearing rates below $0 \cdot 1 \mathrm{~mm} / \mathrm{s}$ it was found that the clay gouge exhibited friction strengthening; this is consistent with data reported by Tika et al. (1996).

Many authors have reported in recent years the results of high-velocity shearing (limited to around $1.3 \mathrm{~m} / \mathrm{s}$ in most cases) in a variety of soil types (Di Toro et al., 2006; Mizoguchi et al., 2007; Ferri et al., 2010; Liao et al., 2011; Han \& Hirose, 2012; Yang et al., 2014) tested, both saturated and unsaturated. The soils tested were typically a mixture of quartz, carbonate minerals and clay minerals. Pore pressures and temperatures were, apparently, never measured. These tests as well as field observations (e.g. the presence of sheared mud in joints adjacent to the main shearing surface; the observation of molten rock injected from the sliding surface into the fault after earthquakes) indicate that the shearing strength reduction may have the following origins: grinding 
of minerals into nanoparticles of low friction; de-hydration of minerals and the associated increase in pore pressure; de-carbonation of calcite and the release of pressurised gas; and melting of minerals, resulting in a viscous material and thermal pressurisation because of the different dilation coefficients of water and minerals, in the case of saturated soils. Lack of saturation enhances the transformation of clay minerals and the release of carbon dioxide, which is an indication of unsaturated samples attaining higher temperatures compared with saturated ones. The results can be explained by considering that saturation allows the reduction of normal effective stress to very small values, in turn reducing heat production despite the high shearing rate. This is consistent with the results of Ujiie \& Tsutsumi (2010) mentioned above.

Shearing rates in creeping slides are not expected to exceed $0 \cdot 1-1 \mathrm{~mm} / \mathrm{s}$ in practice. Therefore the notion of creeping can be explained by friction strengthening with increasing shearing rate, without the need to invoke the concept of viscosity. On the other hand, the extension of friction-rate relationships such as equations (6), (7) or (8) to high shearing rates is more uncertain.

The question of the transformation of a creep motion into an accelerated motion eventually leading to failure has also been approached from a different perspective. Monitoring of slope deformations suggests that the time to failure may be predicted by relating linearly the inverse of velocity with time (Saito, 1965, 1969; Voight, 1978). Helmstetter et al. (2003) discuss the rationale behind these procedures. They further examine the effect of friction strain rate and state dependence by considering the dynamics of a simple sliding block in conjunction with the friction law given by equation (6), elaborated as

$$
\mu=\mu_{0}+A \ln \frac{\dot{\delta}}{\dot{\delta}_{0}}+B \ln \frac{\xi}{\xi_{0}}
$$

where $\mu$ is the friction coefficient, $\dot{\delta}$ is the sliding velocity, $\xi$ is a state variable, subscript 0 refers to reference values and $A$ and $B$ are model parameters. The evolution of the state variable is given by

$$
\frac{\mathrm{d} \xi}{\mathrm{d} t}=1-\frac{\xi \dot{\delta}}{D_{\mathrm{c}}}
$$

where $D_{\mathrm{c}}$ is interpreted as a critical size of asperities of the shearing surface. Variable $\xi$ may model strengthening actions (aging, for instance) or weakening effects for accumulated shear displacements. The authors concluded that the stability of the motion is controlled by the ratio $B / A: B / A>1$ leads to instability, where the slope velocity increases continuously. They suggest that this was the case of Vaiont. If $0<B / A<1$ the motion remains stable and the velocity may increase or decrease towards a constant value. They suggest that this is the case of La Clapière (Follacci et al., 1993). The result is very attractive because it seems to provide a simple and elegant solution to a complex problem. However, this model is unable to explain the fast acceleration of the landslide once it has initiated, for example, the transition from pre-failure velocities of the order of $4 \mathrm{~cm} /$ day to a final velocity of $30 \mathrm{~m} / \mathrm{s}$ in an estimated time of $15 \mathrm{~s}$. It is concluded that a different physical phenomenon should be explored if such acceleration is to be captured. The situation is sketched in Fig. 2. The rateand state-dependent laws of friction seem to be capable of predicting creeping behaviour and even a (slow) transition towards failure (a phenomenon also known as tertiary creep). But they are not capable of explaining very fast slide accelerations starting at a state of creeping velocities. Modelling this transition is the subject of the next section.

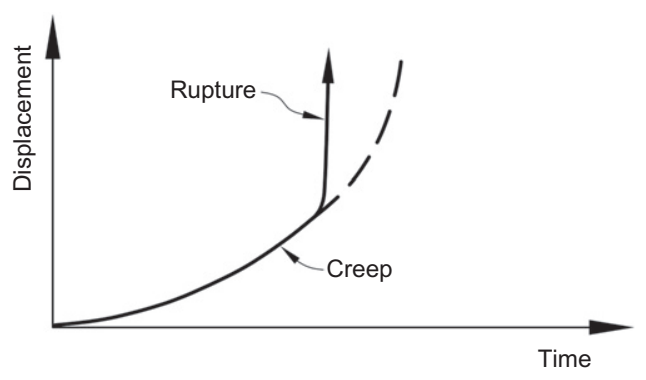

Fig. 2. Creep and rupture: two interacting mechanisms in action

In the remainder of this paper the following ratedependent friction angle will be used

$$
\tan \phi=\tan \phi_{0}\left(1+A \ln \frac{v}{v_{0}}\right)
$$

where $v$ is the sliding velocity across the shear band and $v_{0}$ is a reference velocity. Interpretation of the reported results on residual friction of clayey soils indicates that the rate parameter $A$ can be taken to vary between extremes of $10^{-5}$ and $10^{-2}$. For a baseline friction of $12^{\circ}$ and a reference velocity $v_{0}=0.01 \mathrm{~mm} / \mathrm{min}$, this range implies that a fourorders-of-magnitude increase of velocity will lead to an increase in the residual friction angle between $0.01^{\circ}$ for $A=$ $10^{-5}$, which is negligible, and $5.7^{\circ}$ for $A=10^{-2}$, which represents an extreme, near-50\% increase over the baseline value.

\section{A THM STRAIN-RATE-DEPENDENT SLIDING BLOCK MODEL. PROBLEM FORMULATION Problem description}

Consider a slope inclined at an angle $\beta$ and a planar landslide with constant thickness $D$ (Fig. 3 ). The sliding mass moves as a rigid body and deformations concentrate in a shear band of thickness $2 e$ parallel to the slope surface (Fig. 3). The shearing zone is a large planar surface compared with the band thickness, undergoing uniform deformation. A linear profile of shearing velocity inside the band is assumed. Temperature and pore pressure build-up will be concentrated into the shear band and its vicinity. Therefore the analysis may be formulated as one-dimensional in the direction normal to the band. Water and energy transfer become one-dimensional processes along the spatial coordinate $z$ (Fig. 3). The band thickness is typically small, in the range of a few millimetres or centimetres. Shear bands in real cases are often embedded in thicker layers of claystone or clay-bearing rocks, whose properties the band material may be assumed to share.

Water flow parallel to the slope, over height $h_{\mathrm{w}}$ above the sliding plane, is assumed (Fig. 3).

\section{Dimensionless governing equations}

The landslide motion is described using the dynamics equation. Acceleration results from the difference between gravitational driving forces and frictional resistance forces along the shear band. Frictional forces are controlled by the pore water pressure, which is equal to the sum of the initial pore water pressure, present before movement initiates, and any excess pore water pressure generated during sliding due to shearing-induced heating. Pore pressure and heat dissipation occur simultaneously and are governed by the corresponding mass and energy balance equations inside and outside the shear band.

The following dimensionless variables have been selected to write the governing equations 


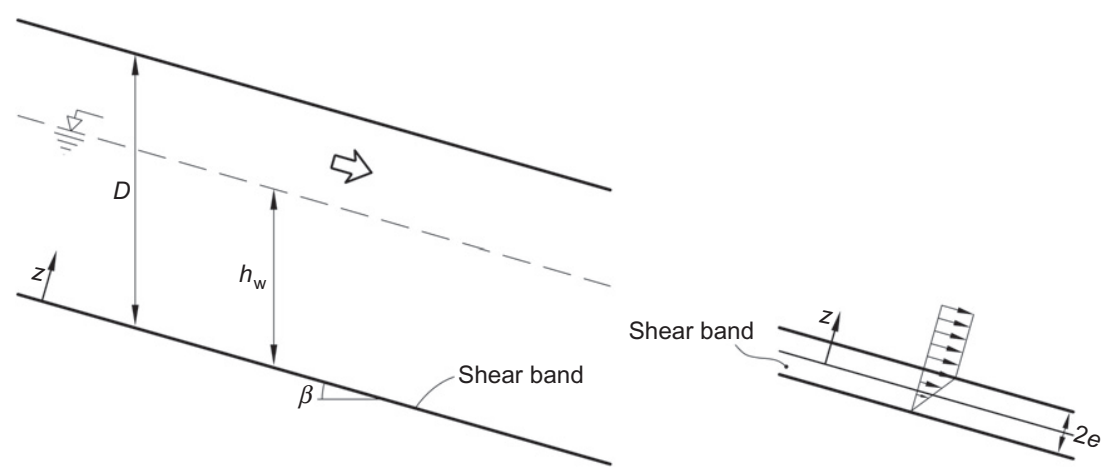

Fig. 3. Geometry of a planar landslide and shear band

$$
\begin{aligned}
& \hat{z}=\frac{z}{D}, \quad \hat{t}=\frac{t \sqrt{g D}}{D}, \quad \hat{\theta}(\hat{z}, \hat{t})=\frac{\theta(z, t)}{\theta_{0}}, \\
& \hat{u}_{\mathrm{w}}(\hat{z}, \hat{t})=\frac{u_{\mathrm{w}}(z, t)}{\rho g D}, \quad \hat{p}_{\mathrm{w}}=\frac{p_{\mathrm{w}}}{\rho g D}, \quad \hat{v}(\hat{t})=\frac{v(t)}{\sqrt{g D}}
\end{aligned}
$$

where $t$ is the time, $\theta$ is the temperature, $u_{\mathrm{w}}$ is the excess pore water pressure, $p_{\mathrm{w}}$ is the initial pore water pressure and $v$ is the landslide velocity. $\rho=n \rho_{\mathrm{w}}+(1-n) \rho_{\mathrm{s}}$ is the density of the saturated soil, expressed in terms of porosity, $n$, and the densities of water $\rho_{\mathrm{w}}$ and solid particles $\rho_{\mathrm{s}} . g$ is the modulus of the gravitational acceleration and $\theta_{0}$ is a reference initial temperature, assumed equal to $10^{\circ} \mathrm{C}$ in the calculations reported below. The governing equations and initial and boundary conditions of the problem are expressed as follows.

Dynamic equilibrium

$$
\frac{\mathrm{d} \hat{v}(\hat{t})}{\mathrm{d} \hat{t}}=\sin (\beta)-\left(\cos (\beta)-\frac{\hat{p}_{\mathrm{wh}}}{\cos (\beta)}-\frac{\hat{u}_{\mathrm{w}}^{\max }(\hat{t})}{\cos (\beta)}\right) \tan \phi^{\prime}
$$

Initial condition, $\hat{v}(\hat{t}=0)=0$

Energy balance equation

$$
\frac{\partial \hat{\theta}(\hat{z}, \hat{t})}{\partial \hat{t}}-\frac{\Gamma}{(\rho c)_{\mathrm{m}} D \sqrt{g D}} \frac{\partial^{2} \hat{\theta}(\hat{z}, \hat{t})}{\partial \hat{z}^{2}}=\hat{H}(\hat{z}, \hat{t})
$$

where

$$
\begin{aligned}
\hat{H}(\hat{z}, \hat{t})= & \frac{\rho g D^{2}}{(\rho c)_{\mathrm{m}} \theta_{0} 2 e}\left(\cos ^{2}(\beta)-\hat{p}_{\mathrm{wh}}-\hat{u}_{\mathrm{w}}^{\max }(\hat{t})\right) \\
& \times \tan \phi^{\prime} \hat{v}(\hat{t}) \quad \text { for } \quad \hat{z} \in[0, e / D] \\
\hat{H}(\hat{z}, \hat{t})= & 0 \quad \hat{z} \in\left(e / D, L_{\theta}\right)
\end{aligned}
$$

Initial and boundary conditions are given by

$$
\left\{\begin{array}{l}
\hat{\theta}(\hat{z}, \hat{t}=0)=1 \\
\left.\frac{\partial \hat{\theta}}{\partial \hat{z}}\right|_{(\hat{z}=0, \hat{t})}=0 \\
\hat{\theta}\left(\hat{z}=e^{-} / D, \hat{t}\right)=\hat{\theta}\left(\hat{z}=e^{+} / D, \hat{t}\right) \\
\left.\frac{\partial \hat{\theta}}{\partial \hat{z}}\right|_{\left(\hat{z}=e^{-} / D, \hat{t}\right)}=\left.\frac{\partial \hat{\theta}}{\partial \hat{z}}\right|_{\left(\hat{z}=e^{+} / D, \hat{t}\right)} \\
\hat{\theta}\left(\hat{z}=L_{\theta} / D, \hat{t}\right)=1
\end{array}\right.
$$

The specific heat of the saturated porous medium is calculated using a weighted average: $(\rho c)_{\mathrm{m}}=n \rho_{\mathrm{w}} c_{\mathrm{w}}+(1-n) \rho_{\mathrm{s}} c_{\mathrm{s}}$, where $c_{\mathrm{w}}$ and $c_{\mathrm{s}}$ are the specific heat of water and solid particles, respectively. Fourier's thermal conductivity is also calculated as a weighted average $\Gamma=n \Gamma_{\mathrm{w}}+(1-n) \Gamma_{\mathrm{s}}$, where $\Gamma_{\mathrm{w}}$ and $\Gamma_{\mathrm{s}}$ are the conductivity of water and solid, respectively. In line with Alonso \& Pinyol (2010b), advective heat transfer is neglected.

The dimensionless source term $\hat{H}(\hat{t})$ in equation (15a) quantifies the heat input into the shear band in terms of the work consumed per unit volume of the material by its shear strength. Outside the band, where the mass moves as a rigid body, no heat is generated (equation (15b)).

Regarding initial and boundary conditions, the first condition (equation (16a)) imposes that initially the shear band and surrounding zone are at the reference temperature. No heat is transferred across the centre of the shear band and therefore no heat flow is imposed at $\hat{z}=0$ (equation (16b)). Continuity of temperature and heat flow should be satisfied on both sides of the shear band (equations (16c) and (16d)). The temperature boundary condition at $\hat{z}=L_{\theta} / D$ (equation (16e)) stipulates that temperature remains unaffected beyond a pre-determined distance $L_{\theta}$ from the axis of the shear band. If taken further away from the shear band than heat flow will reach during the time frame modelled, $L_{\theta}$ does not affect the results.

Mass balance equation

$$
\begin{aligned}
& -\frac{\beta_{\text {soil }} \theta_{0}}{m_{\text {soil }} \rho g D} \frac{\mathrm{d} \hat{\theta}(\hat{z}, \hat{t})}{\mathrm{d} \hat{t}}+\frac{\mathrm{d} \hat{u}_{\mathrm{w}}(\hat{z}, \hat{t})}{\mathrm{d} \hat{t}}-\frac{k}{\gamma_{\mathrm{w}} m_{\text {soil }} D \sqrt{g D}} \frac{\mathrm{d}^{2} \hat{u}_{\mathrm{w}}(\hat{z}, \hat{t})}{\mathrm{d} \hat{z}^{2}} \\
& =0
\end{aligned}
$$

Initial and boundary conditions are given by

$$
\left\{\begin{array}{l}
\hat{u}_{\mathrm{w}}(\hat{z}, \hat{t}=0)=0 \\
\left.\frac{\partial \hat{u}_{\mathrm{w}}}{\partial z}\right|_{(\hat{z}=0, \hat{t})}=0 \\
\hat{u}_{\mathrm{w}}\left(\hat{z}=e^{-} / D, \hat{t}\right)=\hat{u}_{\mathrm{w}}\left(\hat{z}=e^{+} / D, \hat{t}\right) \\
\left.\frac{\partial \hat{u}_{\mathrm{w}}}{\partial z}\right|_{\left(\hat{z}=e^{-} / D, \hat{t}\right)}=\left.\frac{\partial \hat{u}_{\mathrm{w}}}{\partial z}\right|_{\left(\hat{z}=e^{-} / D, \hat{t}\right)} \\
\hat{u}_{\mathrm{w}}\left(\hat{z}=L_{u_{\mathrm{w}}} / D, \hat{t}\right)=0
\end{array}\right.
$$

In the mass balance equation (17), $\beta_{\text {soil }}$ is a weighted average thermal expansion coefficient for saturated soils calculated as: $\beta_{\text {soil }}=n \beta_{\mathrm{w}}+(1-n) \beta_{\mathrm{s}}$, where $\beta_{\mathrm{w}}$ and $\beta_{\mathrm{s}}$ are the thermal expansion coefficients of water and solid particles, respectively. These depend on temperature, for example, Wagner \& Kruse (1998); however, as a first approximation they are assumed here to be constant. $m_{\text {soil }}$ is the compressibility of saturated soil, calculated as $m_{\text {soil }}=m_{v}+n \alpha_{\mathrm{w}}$ where $m_{v}$ and $\alpha_{\mathrm{w}}$ are the coefficients of compressibility of the soil skeleton and the water, respectively. $k$ is the saturated permeability of the soil. 
Initial and boundary conditions are similar to those imposed for heat transfer. The initial value of excess pore pressure is zero (equation (18a)). No water flow crosses the centre of the shear band (equation (18b)). Equations (18c) and (18d) ensure continuity of excess pore pressure and flow rate on both sides of the band. The excess pore pressure is assumed zero beyond a pre-determined distance $L_{u_{\mathrm{w}}}$. If this distance is far enough for excess pore pressure not to develop there, it does not affect the results; otherwise it stipulates the existence of a drainage boundary.

$L_{\theta}$ and/or $L_{u_{\mathrm{w}}}$ may be interpreted as the thickness of the claystone layer containing the shear band: pore pressure and temperature should be maintained constant at its outer boundary. Alternatively, if the layer is in contact with a pervious rock mass, it is reasonable for these conditions to apply at the interface.

Four dimensionless coefficients are naturally defined in the balance and equilibrium equations. They are associated with the physical phenomena describing the problem:

$\Theta=\frac{\Gamma}{(\rho c)_{\mathrm{m}} D \sqrt{g D}}$, coefficient associated with heat flow in the heat balance equation;

$\Psi=\frac{\rho g D^{2}}{(\rho c)_{\mathrm{m}} \theta_{0} 2 e}=\frac{\rho D(\sqrt{g D})^{2}}{(\rho c)_{\mathrm{m}} \theta_{0} 2 e}$, coefficient of the source term in the heat balance equation;

$\Pi=\frac{\beta_{\text {soil }}}{m_{\text {soil }}} \frac{\theta_{0}}{\rho g D}$, coefficient associated with thermal expansion of porous rock in the mass balance equation of water;

$\Sigma=\frac{k}{\gamma_{\mathrm{w}} m_{\text {soil }} D \sqrt{g D}}$, coefficient associated with stress-induced volumetric deformation in the mass balance equation of water.

$\Theta$ is a measure of the thermal dissipation and combines thermal conduction, heat storage, a reference dimension and a reference velocity; $\Psi$ can be interpreted as the ratio between the kinetic energy of the moving mass and the initial heat stored in the shear band, $\Pi$ is a ratio of the thermal expansion of the saturated porous medium with respect to its mechanical compressibility and $\Sigma$ is a dimensionless consolidation coefficient that combines permeability, confined compressibility and the sliding depth.

For a given planar landslide of thickness $D$, the range of variation of the non-dimensional parameters is limited. Properties such as density, Fourier's coefficient, thermal expansion coefficient and the specific heat for common soils and rocks exhibit small variation, especially if compared with other parameters such as permeability. Typical values for these material properties are indicated in Table 2. On the contrary, permeability, $k$, soil compressibility, $m_{v}$, and thickness of the shear band, $e$, may change more significantly.

Table 2. Material properties for water and solid particles

\begin{tabular}{|c|c|c|c|}
\hline Parameter & Symbol & Value & Unit \\
\hline \multicolumn{4}{|l|}{ Water } \\
\hline Density & $\rho_{\mathrm{w}}$ & 1000 & $\mathrm{~kg} / \mathrm{m}^{3}$ \\
\hline $\begin{array}{l}\text { Coefficient of } \\
\text { compressibility }\end{array}$ & $\alpha_{\mathrm{w}}$ & $5 \times 10^{-10}$ & $1 / \mathrm{Pa}$ \\
\hline $\begin{array}{l}\text { Thermal expansion } \\
\text { coefficient }\end{array}$ & $\beta_{\mathrm{w}}$ & $3 \cdot 42 \times 10^{-4}$ & $1 /{ }^{\circ} \mathrm{C}$ \\
\hline Specific heat & $c_{\mathrm{w}}$ & $4 \cdot 186 \times 10^{3}$ & $\mathrm{~J} / \mathrm{kg} \cdot{ }^{\circ} \mathrm{C}$ \\
\hline Conductivity & $\Gamma$ & $0 \cdot 580$ & $\mathrm{~J} / \mathrm{m} \cdot \mathrm{s} \cdot{ }^{\circ} \mathrm{C}$ \\
\hline \multicolumn{4}{|l|}{ Solid particles } \\
\hline Density & $\rho_{\mathrm{s}}$ & 2,700 & $\mathrm{~kg} / \mathrm{m}^{3}$ \\
\hline $\begin{array}{l}\text { Thermal expansion } \\
\text { coefficient }\end{array}$ & $\beta_{\mathrm{s}}$ & $3 \times 10^{-5}$ & $1 /{ }^{\circ} \mathrm{C}$ \\
\hline Specific heat & $c_{\mathrm{s}}$ & $8 \cdot 372 \times 10^{-2}$ & $\mathrm{~J} / \mathrm{kg} \cdot{ }^{\circ} \mathrm{C}$ \\
\hline Conductivity & $\Gamma$ & $0 \cdot 375$ & $\mathrm{~J} / \mathrm{m} \cdot \mathrm{s} \cdot{ }^{\circ} \mathrm{C}$ \\
\hline \multicolumn{4}{|l|}{ Soil } \\
\hline Porosity & $n$ & $0 \cdot 2$ & - \\
\hline
\end{tabular}

Table 3. Typical ranges for permeability, coefficient of compressibility and band thickness

\begin{tabular}{l|l|l|l}
\hline Parameter & Symbol & $\begin{array}{l}\text { Range } \\
\text { of value }\end{array}$ & Unit \\
\hline Permeability & $k$ & $10^{-13}-10^{-5}$ & $\mathrm{~m} / \mathrm{s}$ \\
Coefficient of compressibility & $m_{v}$ & $10^{-10}-10^{-8}$ & $1 / \mathrm{Pa}$ \\
Shear band thickness & $2 e$ & $0 \cdot 001-0 \cdot 05$ & $\mathrm{~m}$ \\
\hline
\end{tabular}

Typical ranges of values of these variables are collected in Table 3 . As a consequence, the dimensionless parameters that may vary significantly depending on the particular case analysed are: $\Psi$, which is inversely proportional to the band thickness; $\Pi$, which is inversely proportional to the band compressibility coefficient; and $\Sigma$, which depends on the ratio of permeability and soil compressibility.

Using Table 2 and Table 3, ranges for the values of the non-dimensional parameters can be established. $\Theta$ is essentially constant and equal to $1 \cdot 27 \times 10^{-9} . \Psi$ depends on the shear band thickness and may vary between 30 and 1800 . $\Pi$ may vary by two orders of magnitude, roughly between $0 \cdot 1$ and 10 , due to the variability of the shear band compressibility coefficient. Finally, $\Sigma$ depends on the ratio between permeability and compressibility so its range of variation is much wider, between $10^{-3}$ and $10^{7}$. Shear bands are often located in highly overconsolidated layers having a wide range of clay mineral content. Their compressibility will be closer to the medium and low values within the range indicated in Table 2, reducing the variability mainly of $\Pi$ but also of $\Sigma$ in practice. Permeability remains as the main source of variability.

\section{Zero thickness shear band}

Idealising the sliding surface as a zero thickness shearing band may be sufficiently close to actual conditions, especially in highly plastic materials where sliding surfaces are often described as smooth and polished planes. In terms of problem formulation and its numerical solution, the hypothesis of zero band thickness presents some advantages: $(a)$ the geometry is simplified and one of the parameters entering the dimensionless formulation, the band thickness, $2 e$, disappears and $(b)$ the discretisation of the domain is simplified because there is no need to discretise the very thin band.

The rate of frictional work expended along the contact plane, per unit of surface, is now calculated as the product between shear strength and velocity. This mechanical work dissipates into heat that enters the rock mass. With reference to Fig. 1, when $2 e=0$, the coordinate $z=0$ indicates the position of the contact plane.

The system of equations governing the problem is similar to the system for finite band thickness. The difference lies in the heat balance equation, which becomes

$$
\frac{\partial \hat{\theta}(\hat{z}, \hat{t})}{\partial \hat{t}}-\frac{\Gamma}{(\rho c)_{\mathrm{m}} D \sqrt{g D}} \frac{\partial^{2} \hat{\theta}(\hat{z}, \hat{t})}{\partial \hat{z}^{2}}=0
$$

with the following initial and boundary conditions

$$
\left\{\begin{array}{l}
\hat{\theta}(\hat{z}, \hat{t}=0)=1 \\
\left.\frac{\partial \hat{\theta}}{\partial \hat{z}}\right|_{(\hat{z}, \hat{t}=0)}=0 \\
\frac{1}{2} H(\hat{t})=-\left.\frac{\Gamma \theta_{0}}{D} \frac{\partial \hat{\theta}}{\partial \hat{z}}\right|_{(\hat{z}=0, \hat{t})} \Rightarrow \frac{\partial \hat{\theta}}{\partial \hat{z}}(\hat{z}=0, \hat{t}) \\
\quad=-\frac{\rho g D^{2} \sqrt{g D}}{2 \Gamma \theta_{0}}\left(\cos ^{2}(\beta)-\hat{p}_{\mathrm{wh}}-\hat{u}_{\mathrm{w}}^{\max }(\hat{t})\right) \tan \phi^{\prime} \hat{v}(\hat{t}) \\
\hat{\theta}\left(\hat{z}=L_{\theta} / D, \hat{t}\right)=1
\end{array}\right.
$$


Note that no heat is generated in the sliding mass, but heat flow is imposed through a boundary flux at $z=0$. Because of symmetry only half of the heat generated is considered. The dimensionless parameters describing this problem remain identical to the case of finite band thickness except for the coefficient associated with the source term in the heat balance equation, which becomes $\Psi=\left[\left(\rho g D^{2} \sqrt{g D}\right) / 2 \Gamma \theta_{0}\right]$. The heat generated at the boundary is now calculated as

$$
H(\hat{t})=\rho g D \sqrt{g D}\left(\cos ^{2}(\beta)-\hat{p}_{\mathrm{wh}}-\hat{u}_{\mathrm{w}}^{\max }(\hat{t})\right) \tan \phi^{\prime} \hat{v}(\hat{t})
$$

\section{Rate effects}

Slow maintained slide displacement rates (creeping) will be explained by considering strain rate effects on strength, following the discussion in the second section entitled 'Strainrate-dependent friction and precursory sliding motions'. The analysis concentrates on active slides irrespective of their initial creeping rate; therefore frictional strength is characterised by a residual friction angle. The effective residual friction strength is defined as the sum of the strength available at velocities lower than a given value of reference $\left(v_{\text {ref }}\right)$ and an additional term that depends on sliding velocity

$\tan \phi=\tan \phi_{0}+f_{\mathrm{v}}$

Recalling the logarithmic law of equation (11)

$$
\begin{gathered}
f_{\mathrm{v}}=A \ln \left(\frac{v}{v_{\text {ref }}}\right)=A \ln \left(\hat{v} \frac{\sqrt{g D}}{v_{\text {ref }}}\right) \\
\text { for } \quad v>v_{\text {ref }} ; \hat{v}>\hat{v}_{\text {ref }}=v_{\text {ref }} / \sqrt{g D} \\
f_{\mathrm{v}}=0 \quad \text { for } v \leq v_{\text {ref }} ; \hat{v} \leq \hat{v}_{\text {ref }}=v_{\text {ref }} / \sqrt{g D}
\end{gathered}
$$

The slope angle $\beta$ and the parameters defining the friction law $\left(\phi_{0}^{\prime}, A, v_{\text {ref }} / \sqrt{g D}\right)$ complete the set of dimensionless parameters governing the problem.

\section{NUMERICAL INTEGRATION}

Equations (13), (14) and (17) form a system of coupled, non-linear partial differential equations that needs to be solved. The use of centred-space forward-time (explicit) finite differences has been the norm in past work (e.g. Vardoulakis, 2002; Alonso et al., 2010; Cecinato et al., 2011; Cecinato \& Zervos, 2012). However, explicit integration requires very small time steps, typically of the order of $10^{-5} \mathrm{~s}$, for numerical stability. Although acceptable when modelling the catastrophic phase of a slide over its final few tens of seconds, this onerous condition makes modelling of the long-term creep behaviour that may precede failure impractical. The alternative explored here is the use of an unconditionally stable implicit scheme that will allow much larger time steps. The ability to adapt the time step during the calculation is also essential, so that long periods of creep where the solution changes by very little can be modelled efficiently. Here the trapezoidal rule is used, which is of order $O\left(\Delta t^{2}\right)$. In principle it is also possible to use a higher order, more accurate multistep method; however, adaptive time stepping will only be possible at the cost of significantly increased complexity, for example as shown by Skeel (1986).

The resulting system of equations must be solved iteratively to calculate at the end of each time step the slide velocity as well as the temperature and excess pore pressure everywhere in the domain. Solution using a full NewtonRaphson method is, however, problematic, as the logarithmic friction law renders the dynamics equation highly non-linear.
Convergence requires time steps typically smaller than $10^{-3} \mathrm{~s}$, defeating the purpose of the implicit scheme.

The strategy adopted was to use a staggered solution scheme: the diffusion equations were solved by NewtonRaphson using the current approximation of the velocity; the dynamics equation was subsequently solved by Pegasus (Dowell \& Jarratt, 1972), a method of the regula falsi family that is known to be fast and efficient in finding roots of non-linear equations. Iterations continued until the residuals of all equations were below tolerance. The time step was increased or decreased based on the rate, or lack of, convergence. The maximum time step used was $24 \mathrm{~h}$. This approach allowed time steps of the order of $10^{5} \mathrm{~s}$ for the most part of an analysis, making the efficient modelling of years of creeping motion possible.

An additional challenge was the location of the far boundary $L_{\theta}$ and $L_{u_{\mathrm{w}}}$. Previous work considered that ambient values of temperature and excess pore pressure are applicable at a distance equal to a small multiple of the shear-band thickness. Although this is valid for rapid heat generation during the final collapse, modelling the creep phase should require a larger domain, as heat and pore water will potentially have the time to travel longer distances. In practice, the presence of a geological feature, such as an interface with pervious rock, may provide a natural boundary within the sliding mass, as discussed previously. For the general case, however, the following numerical approach was adopted: the far boundary was initially considered at a distance ten times the shear-band thickness. If, during the calculation, the value of either the temperature or the excess pore pressure next to the boundary was found to differ by more than $10^{-10}{ }^{\circ} \mathrm{C}$ or $\mathrm{kPa}$, respectively, from the corresponding boundary condition, the domain was expanded by 100 times the shearband thickness before the calculation continued. Therefore, the problem progressively became computationally more expensive; typical calculations started with about 300 unknowns but eventually involved in excess of 300000 . Nevertheless, due to the direct, sparse multi-frontal solver (HSL, 2015) used, all models could run on a desktop computer within hours.

\section{ANALYSIS}

\section{An illustrative example}

The case presented below illustrates the capability of the model to integrate a history of creeping motions and the eventual triggering of a rapid catastrophic motion. Basic parameters are given in Table 1 . The sliding mass is defined by $D=25 \mathrm{~m}, h_{\mathrm{w} 0}=11.05 \mathrm{~m}, \beta=9 \cdot 8^{\circ}, \phi_{0}=12^{\circ}, 2 e=2.5 \mathrm{~mm}$, $m_{v}=1.5 \times 10^{-9} \mathrm{~Pa}^{-1}$ and $k=10^{-9} \mathrm{~m} / \mathrm{s}$. The strain rate effect is characterised by $A=0.014$ and $v_{\text {ref }}=10^{-5} \mathrm{~m} / \mathrm{s}$. An initial temperature $\theta_{0}=10^{\circ} \mathrm{C}$ is assumed. The shear band is centred in a clayey layer $2 \mathrm{~m}$ thick, bounded by pervious rock that is able to maintain the initial pore pressure and temperature.

The slope is initially in strict equilibrium with zero velocity. It is destabilised by increasing the water level to $h_{\mathrm{w}}=12 \mathrm{~m}$. The subsequent history of water level changes is given in Fig. 4(a). There is a transient reduction of $h_{\mathrm{w}}$ from $13 \mathrm{~m}$ to $12.5 \mathrm{~m}$ and a final increase to $14 \mathrm{~m}$. During this final stage the slide suddenly accelerates. Fig. 4 provides the calculated evolution of temperature (Figs 4(b) and 4(c)), excess pore water pressure (Fig. 4(d)), velocity (Fig. 4(e)), displacement (Fig. 4(f)) and friction angle (Fig. 4(g)). Temperature and excess pore pressure increase in the shear band as soon as the slide becomes unstable. The sliding velocity slowly increases; however, strain rate effects contribute to maintaining dynamic equilibrium. The subsequent reduction of water level reduces the sliding velocity and the shear band excess pore pressure and temperature. Similar changes occur to the 


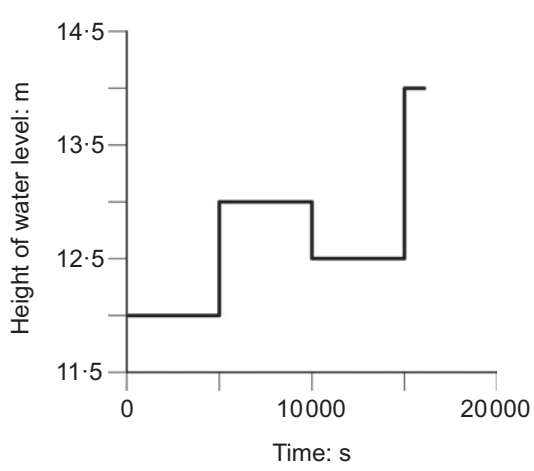

(a)

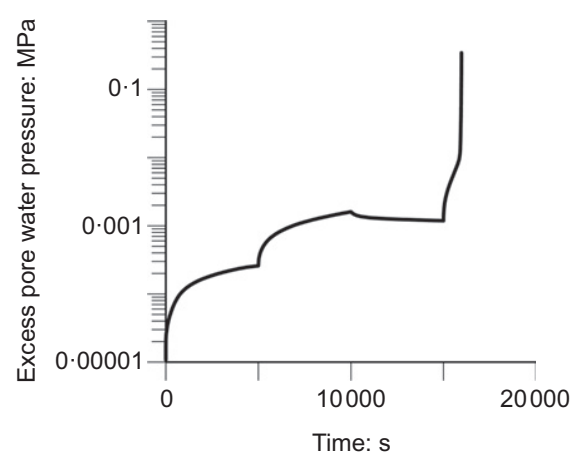

(d)

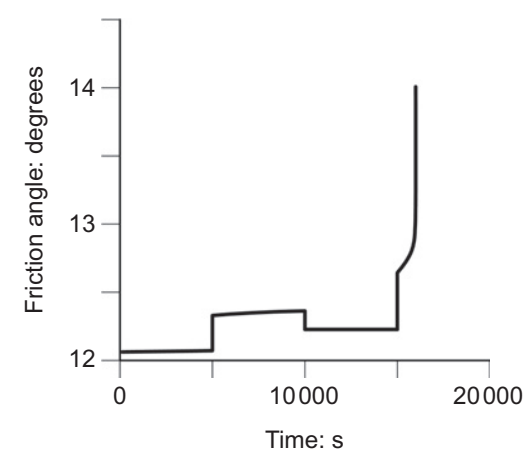

(g)

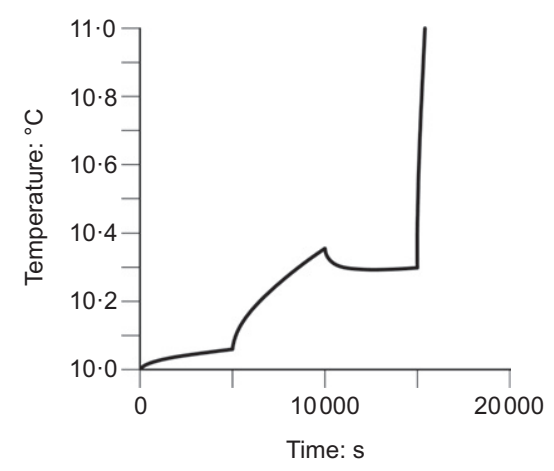

(b)

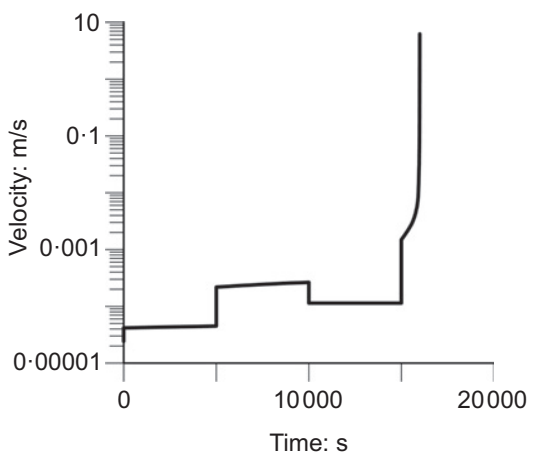

(e)

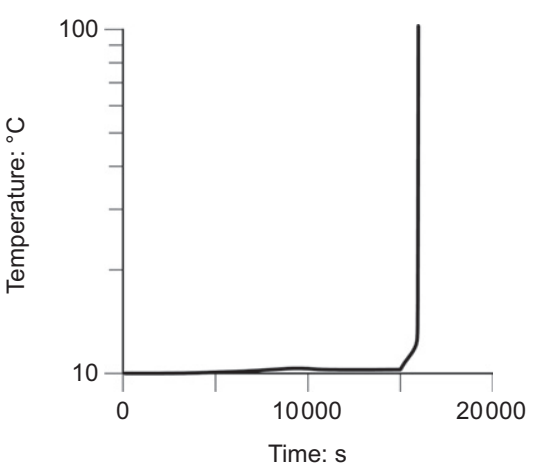

(c)

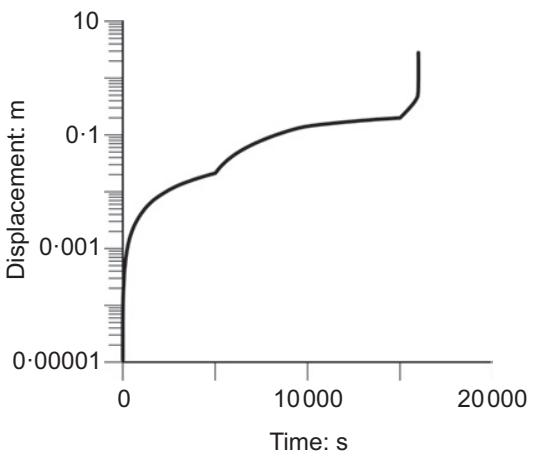

(f)

Fig. 4. Calculated response of an impending planar slide to an imposed variation of: (a) water level; (b) and (c) temperature at centre of shear band; (d) excess pore water pressure at centre of shear band; (e) slide velocity; (f) slide displacement; (g) evolution of friction angle

friction angle, Fig. 4(g), because of strain rate effects. It can be considered that the slope maintains a safety factor $\mathrm{SF}=1$ during the entire creeping period.

When a further increase of water level to $h_{\mathrm{w}}=14 \mathrm{~m}$ is imposed at $t=15000 \mathrm{~s}$, temperature and pore water pressure increase rapidly and strain rate effects are no longer capable of maintaining a state of slow creeping velocity. The slide accelerates because the pore pressure reaches values close to the normal effective stress on the sliding surface, rapidly reducing the frictional resistance there.

Thermal pressurisation affects the behaviour of the slide throughout. However, there is a qualitative change when friction increase, induced by rate effects, is no longer capable of counteracting the strength reduction caused by pore pressure build-up in the shear band. At that time the creeping stage ends and the slope enters a high-acceleration and high-velocity stage promoted by a thermally dominated 'feedback loop': temperature increase-pore pressure increasestrength reduction-velocity increase-temperature increase. From that point onwards strain rate effects no longer play a significant role in the evolution of the slide.
The remainder of this section explores the relationship between these two regimes of slope behaviour. They are intimately linked and particular cases characterised by a sliding geometry and material properties would require a specific analysis. However, the simple planar slide offers insights on the creep-fast sliding coupling. The dimensionless formulation also enhances the generality of the conclusions reached.

\section{Velocity regimes in a planar slide}

Results will be presented for a fixed displacement equal to twice the height of the sliding mass. This is an arbitrary limit; however, analyses of longer runouts are unlikely to be representative due to topographical constraints and/or the resulting fragmentation of the sliding mass.

Rate-independent friction. The previous example is again considered, this time with rate-independent frictional strength. No creeping stage is now possible. This case serves as a reference for the rate-dependent case. 
The landslide is destabilised by imposing an increment of the dimensionless pore water pressure $\left(\hat{p}_{\text {wh }}\right)$ equal to $0 \cdot 0016$, equivalent to increase the water level by $10 \mathrm{~cm}$. It involves a reduction of the $\mathrm{SF}$ from $\mathrm{SF}=1$ to $\mathrm{SF}=0.9978$.

The effect of the shear band thickness is first examined. This parameter only affects $\Psi$, the dimensionless coefficient of the source term in the energy balance equation. Fig. 5 shows the maximum dimensionless velocity for different values of $\Psi$ and $\Sigma$ and a constant $\Pi=1$ value. Since $\Pi$ remains constant for all the cases analysed, variation of $\Sigma$ implies essentially variation of the permeability. The two plots in Fig. 5 present the same information in two different ways. The nearly horizontal lines in Fig. 5(a) indicate that the effect of parameter $\Psi$ on the velocity reached is small. This is also apparent from Fig. 5(b), where the calculated velocities for different band thicknesses essentially overlap. Parameter $\Psi$ directly affects the heat generated in the shear band. The higher its value, that is, the smaller the band thickness, the larger the quantity of heat generated. However, smaller band thickness also means easier dissipation of the heat and excess pore pressure generated within the band towards the surrounding rock mass. Conversely, a thicker band will produce less heat and excess pore pressure, which will take longer to dissipate. The maximum velocity reached is similar to the calculated velocity for a case in which no thermal effects are included (also plotted in Fig. 5). For values of $\Sigma$ lower than $10^{-7}$, no effect of $\Psi$ and $\Sigma$ is observed and the maximum velocity is the same in all cases. The case of zero-thickness shear band is also included in the plot. No significant differences are observed when compared with finite-thickness bands.

Parameter $\Sigma$, which controls the dissipation of excess pore pressure, is key in determining the response of the slide. Values of $\Sigma$ above $10^{-3}$ result in almost no heat-induced effect. Thermally induced excess pore pressure can dissipate quickly in these cases and frictional strength remains slightly smaller than the initial value. The ratio between the shear strength remaining after the maximum runout has been reached and the initial shear strength is plotted in Fig. 6. The shear strength essentially vanishes for values of $\Sigma$ below $10^{-7}$, while for values above $10^{-3}$ it maintains its initial value.

It is concluded that the effect of the dimensionless parameter $\Psi$, which essentially varies with the thickness of the shear band, is quite limited.

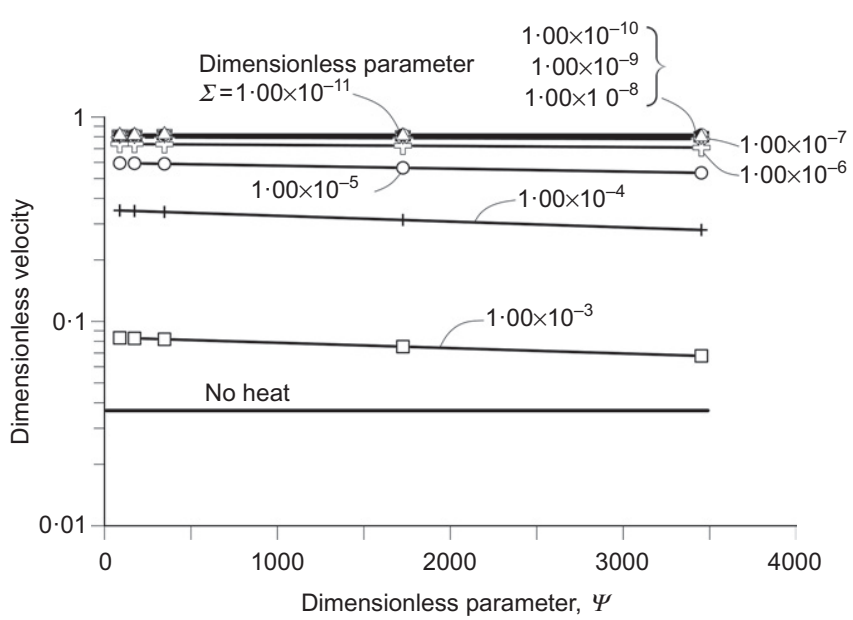

(a)
Parameter $\Sigma$ combines permeability and band compressibility. However, the effect of compressibility cannot be accounted for exclusively by $\Sigma$ because parameter $\Pi$ is inversely proportional to compressibility: it controls the development of pore pressures for a given heat input, which is an effect independent from pore pressure dissipation, which is governed by $\Sigma$. An additional set of calculations were performed to show the combined effect of permeability and compressibility for constant $\Psi=345$, which corresponds to a shear band thickness $2 e=5 \mathrm{~mm}$. The selected values for parameter $\Pi$ imply a wide, about two orders of magnitude, range of variability of the soil compressibility. The values of Table 2 are used for the remaining parameters. The results are plotted in Fig. 7.

Figure 7 shows, as well as Fig. 5(b) for $\Pi=1$, that there is a range of dimensionless consolidation coefficients $\Sigma$ that separates a high-velocity regime (for low $\Sigma$ values) from a low-velocity-, no-heat-effect regime (for high $\Sigma$ values). The observed trends in the variation of velocity with parameter $\Sigma$ are similar for all $\Pi$ values. Reducing $\Pi$, that is, increasing band stiffness, decreases the threshold $\Sigma$ range separating high- and low-velocity regimes. In other words, given a value of $\Sigma$, lower values of $\Pi$, which control the heat-induced pore water pressure, result in lower sliding velocity.

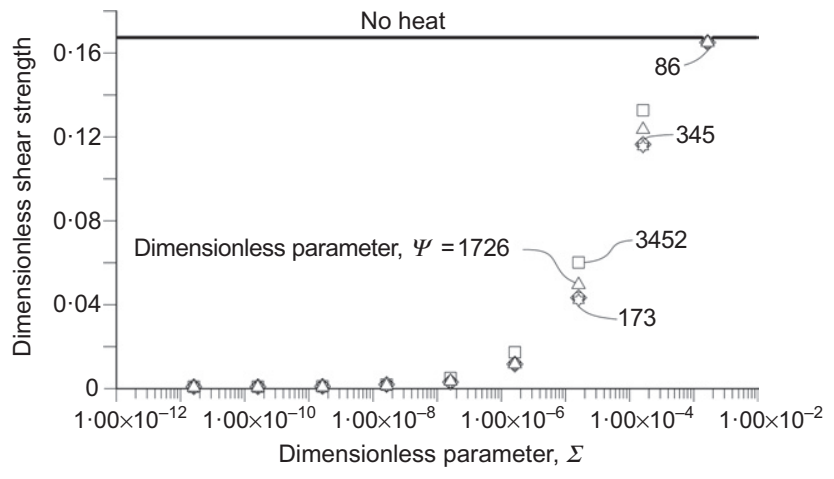

Fig. 6. Ratio of final and initial shear strength for different values of two dimensionless parameters: parameter $\Psi$ (coefficient of heat source term in the energy balance equation) and $\Sigma$ (coefficient of consolidation in the mass balance equation of water flow). $\Pi$ (coefficient of rate of temperature change in the mass balance equation) is equal to 1. Rate-independent friction 


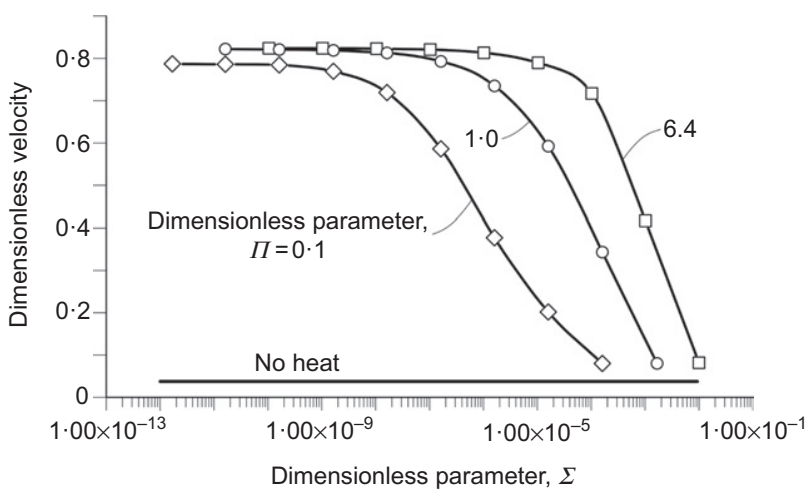

Fig. 7. Dimensionless velocity reached at $50 \mathrm{~m}$ of displacement for different values of two dimensionless parameters: parameter $\Pi$ (coefficient of rate of temperature change in the mass balance equation) and $\Sigma$ (coefficient of consolidation in the mass balance equation of water flow). $\Psi$, the coefficient of heat in the energy balance equation, is equal to 345 . Rate-independent friction

Rate-dependent friction. Consider now the effect of ratedependent friction. Material properties given in Table 2 have also been adopted in the cases presented in this section. A base case for discussion is defined by using the frictional law of equations (19) and (20), for $A=4 \cdot 7 \times 10^{-3}$ and a reference velocity $\hat{v}_{\text {ref }}=6.4 \times 10^{-7}$. The effect of these parameters on the gain in strength with velocity is plotted in Fig. 8. This rate-dependent law is within the range of experimental results measured at low to moderate shearing velocities (say, below $0 \cdot 1 \mathrm{~m} / \mathrm{s}$ ). Above this velocity thermal pressurisation and other phenomena discussed before contribute to the measured rate dependence. However, the plot is extended to high velocities to show the maximum contribution that may be expected from rate effects at high shearing speeds. The parameters chosen imply an increment of $7 \%$, close to one degree, for high sliding velocity $(30 \mathrm{~m} / \mathrm{s})$. The

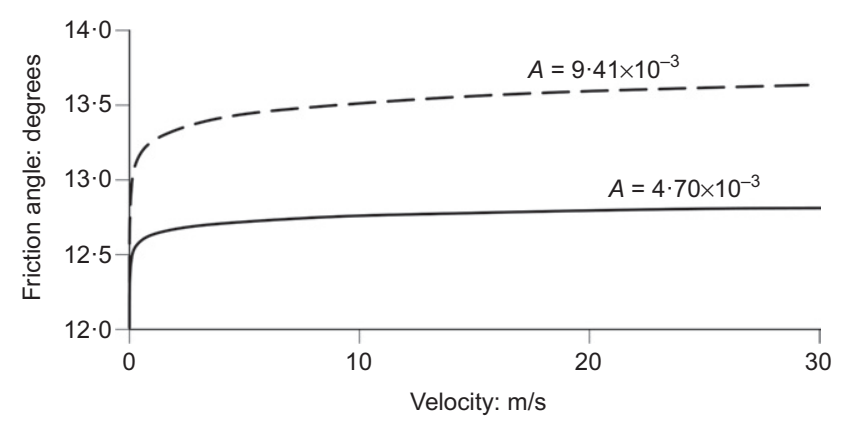

(a)

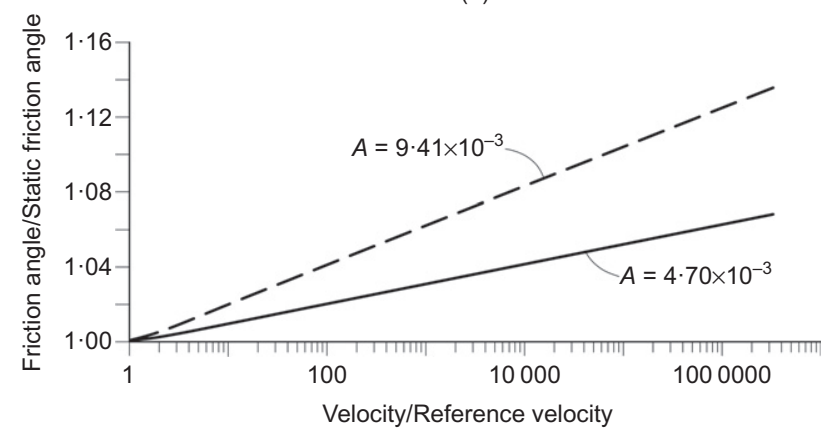

(b)

Fig. 8. Friction angle as a function of shearing velocity for two different $\boldsymbol{A}$ parameters: (a) friction angle plotted against velocity; (b) ratio between friction angle and static friction angle associated with $\log$ velocity values lower than a reference velocity $\left(\hat{v}_{\text {ref }}=6.4 \times 10^{-7}\right)$ rate-dependent strength increases quickly at low velocity and then levels off. Results for a different value of parameter $A$, used in the discussion below, are also plotted in Fig. 8.

The slide is destabilised by imposing a $1 \mathrm{~m}$ increment of the water level. This reduces the SF from 1 to 0.98 . Limit equilibrium for this water level is reached for a friction angle equal to $12 \cdot 32^{\circ}, 2 \cdot 7 \%$ higher than the static friction angle associated with velocities lower than the reference creeping velocity.

The base case was analysed for different values of the $\Pi$ and $\Sigma$ parameters. The band-thickness-controlled parameter $\Psi$ is considered constant and equal to 345 , as its effect has been shown to be insignificant. The results in terms of maximum dimensionless velocity are plotted in Fig. 9. The case where thermal effects are ignored is added to the figure; in that case dynamic equilibrium is reached for a dimensionless velocity of $4.6 \times 10^{-5}$ equivalent to $7 \cdot 2 \times 10^{-4} \mathrm{~m} / \mathrm{s}$, a reference velocity that depends only on the safety factor attained immediately after the initial instability (equation (1)).

When thermal effects are considered, the response observed is similar for the different values of parameter $\Pi$ selected. A narrow range of $\Sigma$ values separates fast and slow sliding regimes. If compared with the no-rate-effect case (Fig. 5(b)) the calculated sliding velocities are now higher. This is a consequence of the stronger initial trigger imposed to initiate the slide run-out $\left(\Delta h_{\mathrm{w}}\right.$ is now $1 \mathrm{~m}$ against $\Delta h_{\mathrm{w}}=$ $0 \cdot 1 \mathrm{~m}$ in the previous case).

The effect of parameter $\Pi$ is similar to the effect observed in cases where rate effects were not included. However, the threshold range of $\Sigma$ values separating the slow and fast sliding regimes decreases when a rate effect on friction is included. This becomes apparent by comparing Fig. 9 and Fig. 7. In other words, rate effects extend the range of 'safe' cases, that is, of slopes that will not accelerate due to thermal pressurisation effects. It appears also that the threshold $\Sigma$ range is narrower in Fig. 9 (rate effects included), compared with Fig. 6 (no rate effects).

Figure 10 presents the maximum temperature in the centre of the shear band for the cases plotted in Fig. 9. If the landslide reaches a high velocity quickly, as is the case for $\Sigma$ lower than $10^{-9}$, the shear-band temperature remains relatively low. The temperature also remains low, almost constant, in those cases where the velocity remains low, in a creeping mode, when $\Sigma$ is higher than $10^{-5}$. Maximum values of temperature are reached in intermediate cases, where the excess pore pressure rises relatively slowly and the velocity, although it may eventually become very high, increases at a

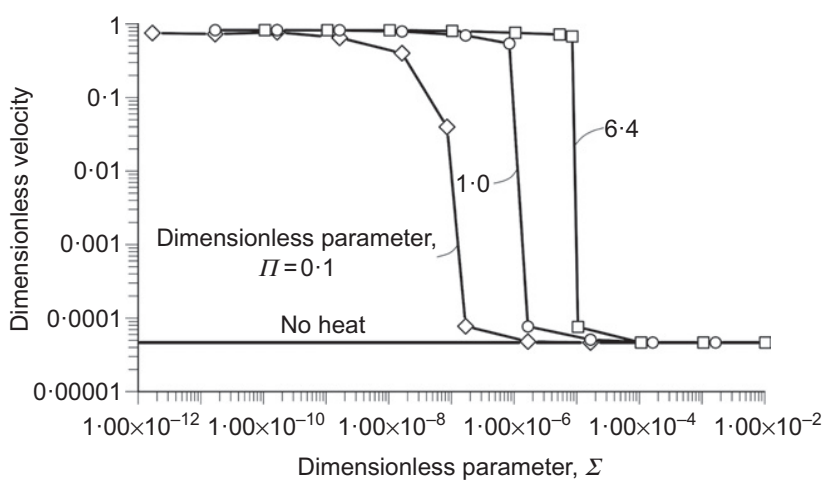

Fig. 9. Dimensionless maximum velocity in terms of dimensionless parameters $\Pi$ (coefficient of rate of temperature change in the mass balance equation) and $\Sigma$ (coefficient of consolidation in the mass balance equation of water flow). $\Psi$ (coefficient of heat source term in the energy balance equation) is equal to 345 . Rate-dependent friction parameters: $A=4.7 \times 10^{-3}$ and $\hat{v}_{\text {ref }}=6.4 \times 10^{-7}$ 


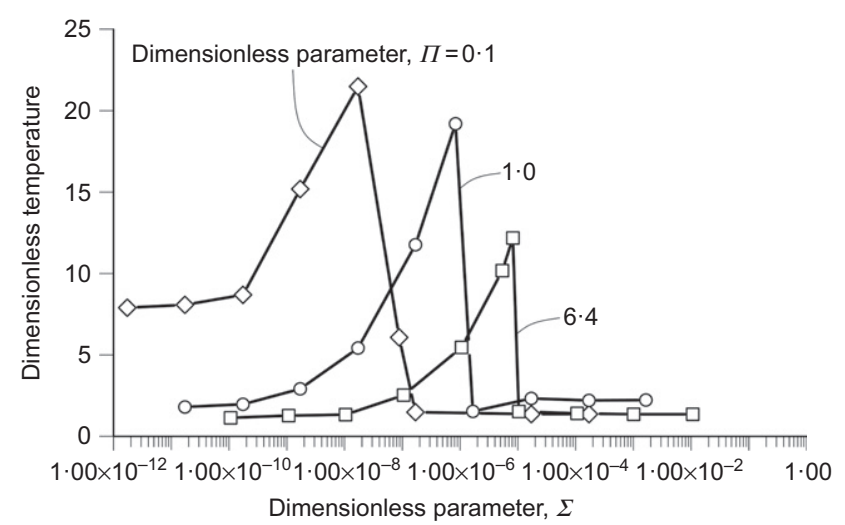

Fig. 10. Dimensionless temperature for different dimensionless parameters: parameter $\Pi$ (coefficient of rate of temperature change in the mass balance equation) and $\Sigma$ (coefficient of consolidation in the mass balance equation of water flow). $\Psi$ (coefficient of heat source term in the energy balance equation) is equal to 345 . Rate-dependent friction with $A=4.7 \times 10^{-3}$ and a reference velocity equal to $\hat{v}_{\text {ref }}=6.4 \times 10^{-7}$

slower pace. The acceleration of the slide is in fact a critical factor controlling the development of temperature.

Increasing the rate-dependent component of friction has been shown to have a significant effect in reducing the threshold permeability (through $\Sigma$ ) that leads to a fast sliding regime. This is further shown in Fig. 11 where the maximum velocity is plotted in terms of $\Sigma$ for three $A$ values (see Fig. 8 for their effect on friction increase). In all cases $\Psi=345$ and $\Pi=1 \cdot 0$. As expected, the creep velocity when thermal effects are ignored (or $\Sigma$ has a high value) decreases for increasing $A$. It is noted that for relatively low values of $\Sigma$, when excess pore pressure dissipation is slow, the maximum velocity attained is similar in all cases irrespective of the considered rate dependence of friction. When thermal effects develop they dominate the sliding behaviour. However, the development of heat-induced pore pressure build-up depends on the creeping history. This relevant issue is discussed in more detail in the next section.

\section{Evolution of motion. Creep-thermo-mechanical interactions}

Attention is now focused on the effect of the rate of friction increase on the blow-up time, that is, the time after initiation at which the slope enters a final catastrophic phase.

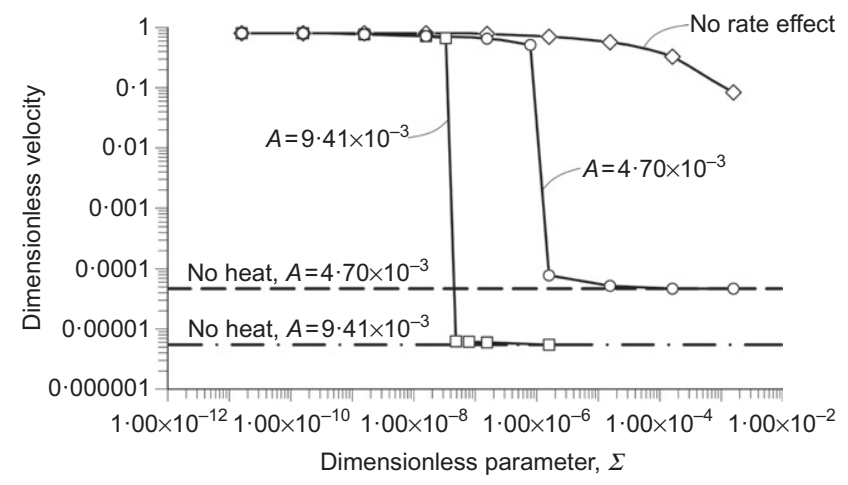

Fig. 11. Dimensionless velocity in terms of dimensionless parameters $\Pi$ (coefficient of rate of temperature change in the mass balance equation) and $\Sigma$ (coefficient of consolidation in the mass balance equation of water flow) for three values of the rate effect parameter $A$. $\Psi$ (coefficient of heat source term in the energy balance equation) is equal to 345 . In all cases plotted, $v_{\text {ref }}=10^{-5} \mathrm{~m} / \mathrm{s}$
Calculations are performed for a planar slide with $D=240 \mathrm{~m}$, base friction angle of $12^{\circ}$ and slope angle of $9 \cdot 8^{\circ}$. An unbounded domain is assumed and a maximum runout of $2 D=480 \mathrm{~m}$ is considered.

To investigate the effect of the rate parameter $A$, a set of analyses is run where the slide is triggered by a minuscule increase of $h_{\mathrm{w}}$ by $0.025 \%$ above the strict equilibrium value, resulting to a change in the safety factor $\delta S F=6 \times 10^{-5}$. In the case of rate-independent friction (i.e. $A=0$ ), catastrophic failure occurs immediately; the slide is classified as 'rapid' (IUGS/International Working Group on Landslides, 1995) 2 $\mathrm{s}$ after initiation and, within a few more seconds, frictional heating leads to high temperature and excess pore pressure almost equal to the overburden stress.

The introduction of even a very mild rate effect, for example, $A=10^{-5}$, corresponding to a negligible increase in friction angle by $0.01^{\circ}$ for a $10^{4}$-fold increase in velocity, suppresses catastrophic acceleration and leads to creep at constant velocity. The magnitude of the velocity attained is governed by the rate parameter $A$; for $A=10^{-5}$ it is $22 \mathrm{~cm} /$ day and drops to $1.5 \mathrm{~cm} /$ day for $A=10^{-3}$, classifying both slides as 'slow' (IUGS/International Working Group on Landslides, 1995). The temperature increases by $10^{\circ} \mathrm{C}$ or less and the excess pore pressure generated is negligible.

To further explore the effect of the rate parameter a second set of analyses is run, where the slide is triggered by a more substantial increase of the groundwater level, resulting to $\mathrm{SF}=0 \cdot 99$. Fig. 12 summarises the results.

In the case of rate-independent friction $A=0$ but also for any $A \leq 10^{-4}$, high temperature and excess pore pressure occur almost immediately and lead to catastrophic failure. For $A=5 \times 10^{-4}$ a transitional behaviour is observed, where the slide first creeps with near-constant velocity for the first $15 \mathrm{~s}$ before accelerating to catastrophic failure, while for $A>5 \times 10^{-4}$ the slide creeps with 'moderate' (IUGS/International Working Group on Landslides, 1995) constant velocity. Therefore a threshold value $A_{\text {crit }}$ of the rate parameter must exist, that determines whether catastrophic acceleration will occur; in this case $6 \times 10^{-4}>$ $A_{\text {crit }}>5 \times 10^{-4}$. This is further explored using models for a range of values in this interval. Fig. 12 shows that even small changes, of the order of $2 \%$, of the rate parameter can have order-of magnitude impact on the duration of the creep phase, although the predicted creep velocity is less sensitive. For comparison, Fig. 12 also presents the baseline velocity, that is, the constant creep velocity each slide would attain if thermal effects were ignored: it is evident that, even where thermal effects do not eventually lead to catastrophic collapse, they still increase slide velocity by at least one order of magnitude.

It is also interesting to note that it is the rate of temperature increase that controls excess pore pressure generation, and

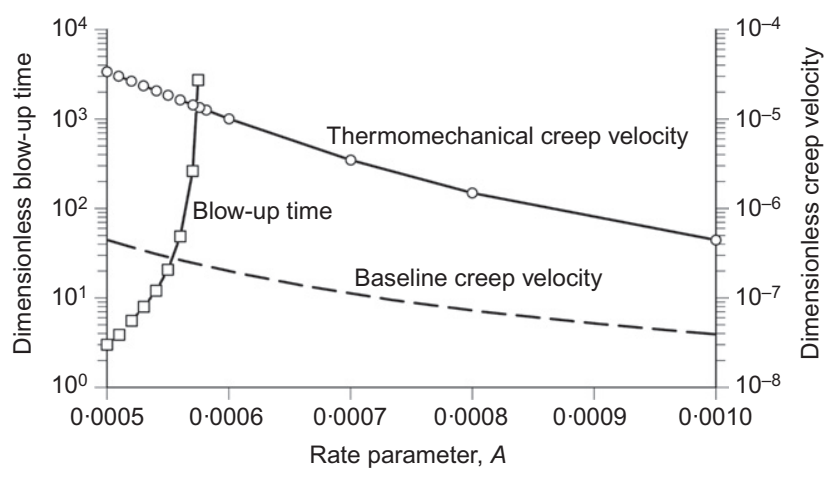

Fig. 12. Effect of rate parameter on creep velocity and blow-up time 
thus the associated loss of strength that leads to catastrophic failure. If the time scale of heat generation is large enough the induced excess pore pressures may dissipate before thermal pressurisation occurs, irrespectively of how high the temperature attained is. For a given rate of heat production, the rate of excess pore pressure generation will depend on soil permeability. It is thus expected that permeability, therefore the value of parameter $\Sigma$, will influence both the creep velocity and the timing of a possible catastrophic failure.

To further investigate the impact of parameter $\Sigma$, a set of analyses is run with the same trigger, rate parameter $A=5 \cdot 75 \times 10^{-4}$ and $\Sigma$ varying between $\Sigma=6 \times 10^{-8}$ and $\Sigma=$ $6 \times 10^{-13}$. The results are summarised in Fig. 13 .

Lower values of $\Sigma$ lead to faster development of excess pore pressure and earlier onset of a catastrophic phase. As $\Sigma$ increases so does the duration of the pre-failure creep phase; this relationship is highly non-linear and, as was the case for the rate parameter, a threshold value $\Sigma_{\text {crit }}$ exists above which a catastrophic phase is never reached. In this case $\Sigma_{\text {crit }} \cong$ $6 \times 10^{-11}$; note how, close to that value, increasing the value of $\Sigma$ by just $2 \%$ results in an increase in the duration of the creep phase by a factor of almost three. Fig. 13 further shows that, for the parameters used here, the velocity of the slide during the creep phase is essentially unaffected by the permeability; the baseline velocity is again plotted for comparison.

Finally, it was found that the maximum temperature that develops in the shear band increases with permeability, regardless of whether a catastrophic phase is eventually reached. This is a direct consequence of the strong influence of permeability on the rate of excess pore pressure generation: the lower the permeability, the faster excess pore pressure rises and effective stress drops, therefore reducing the rate of energy dissipation into heat. Conversely, the higher the permeability the higher the rate of heat production necessary to achieve pressurisation; in fact, models that do not predict a final catastrophic phase consistently attain higher shear-band temperature than models that do.

\section{Compound geometry. Creep-thermo-mechanical interactions}

Previous sections analyse the landslide evolution including two phenomena that work in opposite directions: the heatdriven acceleration of the landslide and the stabilising effect of friction rate effects. In a planar geometry the slide remains always in motion. The creeping velocity, away from blow-up, depends on the magnitude of the destabilisation factors, the intensity of rate effects and additional properties of the shear band, notably its permeability. But other sliding geometries are common. A good example is Vaiont, which may be conceptualised as an evolutionary two-block mechanism (Pinyol \& Alonso, 2010b). The sliding motion results in a reduction

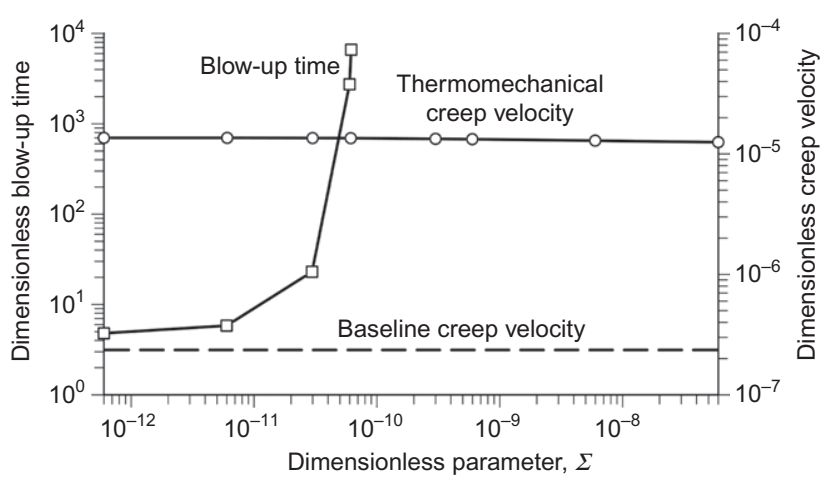

Fig. 13. Effect of the dimensionless parameter $\Sigma$ (coefficient of consolidation in the mass balance equation of water flow) on creep velocity and blow-up time of the mass of the upper unstable wedge and a parallel increase of the mass of the stabilising lower wedge. This is a self-stabilising mechanism unlike the single block case. The effect of this major change in the kinematic description of the landslide is explored here.

Consider the two-block mechanism given in Fig. 14. The interaction between the two sliding blocks is given by the axial force on the hinged 'rod' connecting the blocks. Changes in water pressure act only on the lower block. In the cases solved both wedges have the same thickness but different initial length. Equations of dynamic equilibrium were written for the two interacting blocks. Balance equations (water flow, energy) were formulated for each of the two blocks, following the previous discussion. A zero-thickness band was adopted in the two blocks. The following example was analysed: block thickness, $25 \mathrm{~m}$; the upper and lower blocks are $60 \mathrm{~m}$ and $120 \mathrm{~m}$ long and slide on a plane inclined $37^{\circ}$ and $0^{\circ}$, respectively. The remaining physical constants are identical to the planar slides analysed previously. The stiffness coefficient, $m_{v}=1.5 \times 10^{-9} \mathrm{~Pa}^{-1}$. It leads to the following constant dimensionless parameters for the case analysed: $\Theta=1.27 \times 10^{-9}, \Psi=2 \cdot 72 \times 10^{7}$ and $\Pi=1$. The landslide is destabilised by increasing the water pressure on the sliding surface of the lower block ( $\hat{p}_{\text {wh }}$ increases by 0.04 , which is equivalent to increasing the water level by $1 \mathrm{~m}$ ).

The calculated evolution of velocity and run-out if no friction rate effects are considered is given in Fig. 15.

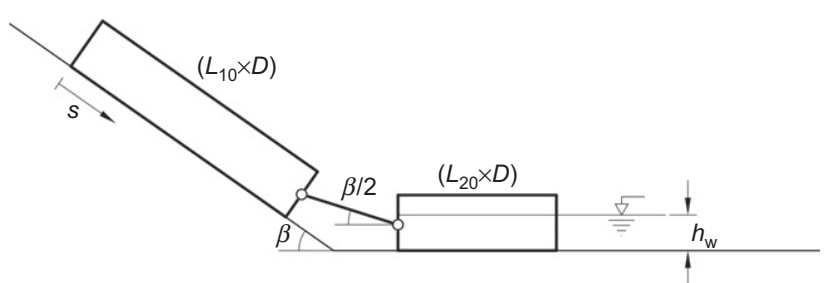

(a)

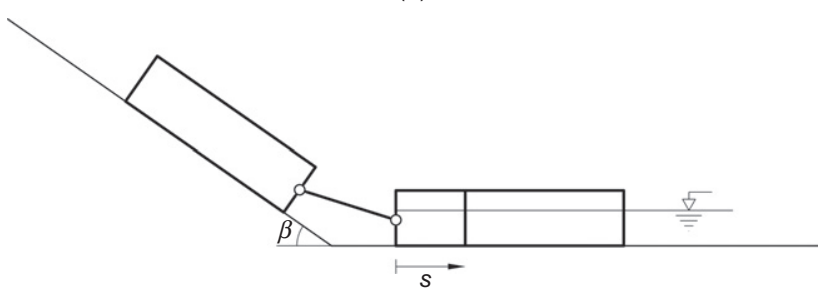

(b)

Fig. 14. The two-block model analysed

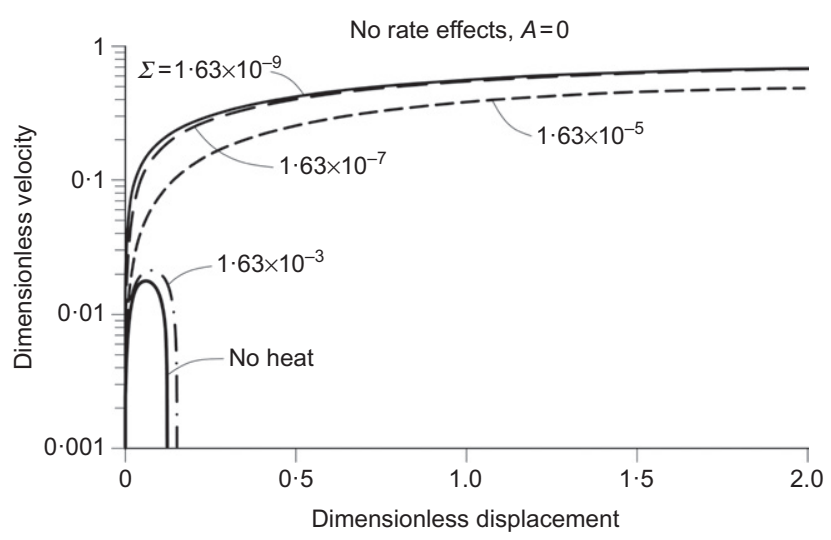

Fig. 15. Thermal analysis of two-block model; no rate effect on friction $(A=0$ ). Effect of dimensionless parameter $\Sigma$ (coefficient of consolidation in the mass balance equation of water flow) on velocity and run-out 


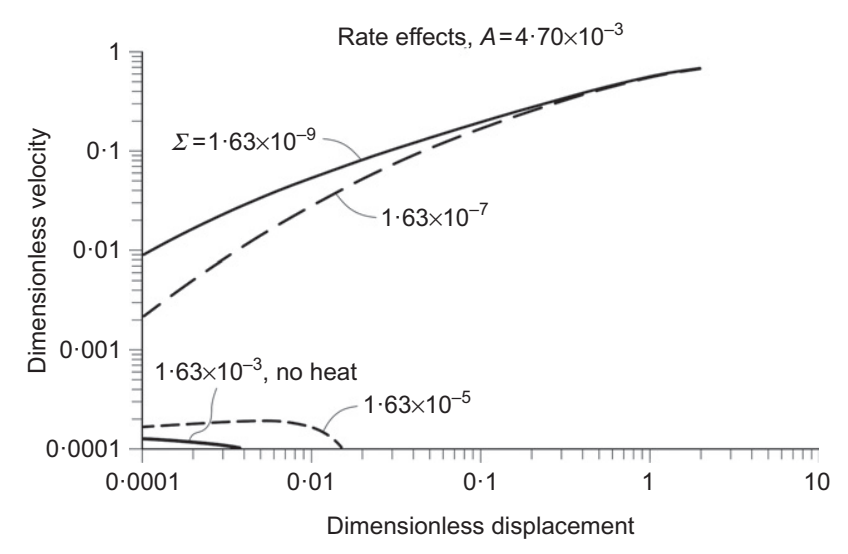

Fig. 16. Thermal analysis of two-block model; rate effect on friction characterised by $A=4 \cdot 7 \times 10^{-3}$ and a reference velocity equal to $\hat{v}_{\text {ref }}=$ $6 \cdot 4 \times 10^{-7}$. Effect of band permeability on velocity and run-out

The effect of $\Sigma$, which depends on permeability in the vicinity of the shear band, is highlighted. Low values, below $1.63 \times$ $10^{-7} \mathrm{~m} / \mathrm{s}$, lead to a slide blow-up. This is also the case for a planar slide. However, the main difference of the compound mechanism is that the slide is able to stop, for high band permeability, as a consequence of the weight transfer between upper and lower blocks. Note also that the thermal effect results in some increase of the run-out and velocity if compared with the no thermal pressurisation analysis.

Friction rate effects, for the same case, are shown in Fig. 16 $\left(A=4 \cdot 7 \times 10^{-3}\right)$. If conditions lead to thermal blow-up, rate effects and slide geometry become largely irrelevant in controlling the sliding velocity and run-out. However, if blow-up conditions are not attained, rate effects play a significant role: they reduce the $\Sigma$ threshold between fast and creeping regimes of the slope and run-out and velocity during the transient motion of the slide after initial instability is significantly reduced. This becomes apparent by comparing Fig. 15 and Fig. 16.

\section{CONCLUSIONS}

Known cases of rapid landslides can only be explained by negligible shear strength acting on the main failure surface. Among the proposed mechanisms of strength reduction, thermal pressurisation of pore water in saturated shear bands may explain a fast accelerated motion as well as a transition from creeping to fast regimes in cases of landslide reactivation. Measured strain rate effects on friction, at low to moderate shearing rates, suggest a linear increase in friction with the logarithm of shearing velocity, a relationship supported by basic friction concepts.

A dynamic modelling of landslide motion, which integrates strain rate effects and thermal interactions in a deforming shear band, provides considerable insights into the evolution of the sliding velocity and its eventual blow-up, when thermal pressurisation dominates the slide motion. A model of this kind, initially developed for planar landslides, has been described by a set of dimensionless balance and equilibrium equations. Four dimensionless constitutive coefficients which control the slide movement were derived. It was found that the shear-band permeability and, to a lesser extent, its compressibility, dominate the entire phenomenon. The set of equations require a numerical solution. A novel staggered implicit integration procedure has been proposed. It is capable of handling, within reasonable computational times, a long creeping history and a sudden final blow-up.
Transition from a slow creeping-like motion to fast acceleration is quite sharp in terms of a dimensionless 'consolidation' coefficient which relates band permeability and stiffness as well as the height of the sliding mass. This threshold is significantly affected by friction rate effects in the sense that increasing rate effects reduces the range of shearband properties leading to blow-up phenomena. Given a creeping motion of a specific landslide, time to blow-up is very sensitive to strain rate effects. Beyond a certain value of the rate parameter, blow-up does not seem to be possible within realistic runout distances.

The paper also examines the behaviour of compound slide geometries, in particular those consisting of a self-stabilising mechanism. If blow-up conditions develop, the slide accelerates as much as a planar slide. However, the creeping stage is also controlled, in addition to aspects valid for planar slides, by geometrical details and the evolutionary changes in slide geometry.

Finally, although the intention of the paper was to provide a theoretical investigation of the problem rather than an analysis of a specific landslide, the models presented can be readily used on appropriate real cases, at least as a backanalysis tool. Predictive modelling is also possible in principle; however, a pertinent issue in this respect is the calibration of material parameters, especially the rate parameter, which may have a significant impact on predictions.

\section{NOTATION}

$A$ model parameter defining the effect of velocity on strength

$a$ model parameter defining the effect of strain rate on friction angle

$B$ model parameter defining the effect of a state parameter on strength

$c_{\mathrm{s}} \quad$ specific heat of solid particles

$c_{\mathrm{w}}$ specific heat of water

$D$ planar landslide thickness

$E$ energy barrier

$E_{1}$ reference energy barrier

$e$ thickness of shear band

$f^{*} \quad$ basic friction for $v=v^{*}$ and $\psi=0$

$f_{\mathrm{v}}$ function defining the effect of sliding velocity on friction angle

$g$ modulus of gravitational acceleration

$\hat{H}$ dimensionless heat generated in shear band

$h_{\mathrm{w}} \quad$ water height above sliding plane

$k$ saturated permeability

$L_{u_{\mathrm{w}}} \quad z$ coordinate where a boundary condition for excess pore water pressure is applied

$L_{\theta} \quad z$ coordinate where a boundary condition for temperature is applied

$\hat{L}_{\theta} \quad$ dimensionless $L_{\theta}$

$m_{\text {soil }}$ compressibility coefficient of soil skeleton

$m_{v}$ oedometric compressibility coefficient of soil

$n$ porosity

$p_{\mathrm{w}}$ initial pore water pressure

$\hat{p}_{\mathrm{w}}$ dimensionless initial pore water pressure

$R$ universal gas constant

$T$ absolute temperature

$t$ time

$u_{\mathrm{w}}$ excess pore water pressure

$\hat{u}_{\mathrm{w}}$ dimensionless excess pore water pressure

$\hat{u}_{\mathrm{w}}^{\max }$ dimensionless maximum excess pore water pressure

$v \quad$ sliding velocity

$v^{*} \quad$ velocity below which friction does not depend on velocity

$\hat{v}$ dimensionless sliding velocity

$v_{\text {ref }}$ reference velocity

$\hat{v}_{\text {ref }}$ dimensionless reference velocity

$v_{1}$ reference shearing rate

$z$ vertical spatial coordinate

$\hat{z}$ dimensionless vertical spatial coordinate

$\alpha_{\mathrm{w}}$ compressibility coefficient of water

$\beta$ inclination of sliding surface 
$\beta_{\mathrm{s}} \quad$ thermal expansion coefficient of solid particles

$\beta_{\text {soil }}$ thermal expansion coefficient of saturated porous media

$\beta_{\mathrm{w}}$ thermal expansion coefficient of water

$\Gamma \quad$ Fourier's thermal conductivity of saturated porous media

$\Gamma_{\mathrm{s}} \quad$ Fourier's thermal conductivity of solid particles

$\Gamma_{\mathrm{w}} \quad$ Fourier's thermal conductivity of water

$\gamma_{\mathrm{w}} \quad$ water specific weight

$\dot{\delta} \quad$ sliding velocity

$\dot{\varepsilon} \quad$ strain rate

$\dot{\varepsilon}_{0} \quad$ reference strain rate

$\Theta$ dimensionless coefficient associated with heat flow in the heat balance equation

$\theta$ temperature

$\hat{\theta}$ dimensionless temperature

$\theta_{0}$ reference temperature

$\mu$ friction coefficient

$\mu_{0} \quad$ reference friction coefficient

$\xi$ state variable which accounts for strengthening and weakening effects on the friction coefficient

$\xi_{0} \quad$ reference value of $\xi$

$\Pi$ dimensionless coefficient associated with thermal expansion of porous rock in the mass balance equation of water

$\rho$ density of saturated porous media

$\rho_{\mathrm{s}} \quad$ density of solid particles

$\rho_{\mathrm{w}} \quad$ water density

$(\rho c)_{\mathrm{s}} \quad$ specific heat of saturated porous media

$\Sigma$ dimensionless coefficient associated with stress-induced volumetric deformation in the mass balance equation of water

$\sigma$ normal stress to sliding plane

$\sigma_{\mathrm{c}}$ normal stress to sliding plane acting at molecular scale

$\tau$ shear stress along sliding plane

$\tau_{\mathrm{c}} \quad$ shear adhesion stress acting at molecular scale

$\phi^{\prime} \quad$ effective friction angle

$\phi_{0}{ }^{\prime}$ reference frictional angle associated with a reference strain rate $\left(\dot{\varepsilon}_{0}\right)$

$\Psi$ dimensionless coefficient associated with source term in the heat balance equation

$\bar{\Psi} \quad$ variable to include effects other than those associated with shearing velocity on frictional strength

$\Omega$ active volume of contact bonds

\section{REFERENCES}

Alcántara-Ayala, I. \& Domínguez-Morales, L. (2008). The San Juan de Grijalva catastrophic landslide, Chiapas, Mexico: lessons learnt. In Proceedings of the 1st world landslide forum, Tokyo, Japan (eds K. Sassa and P. Canuti), pp. 96-99. Berlin, Germany: Springer.

Alonso, E. E. \& Pinyol, N. M. (2014). Slope stability in slightly fissured claystones and marls. Landslides, http://dx.doi.org/10. 1007/s10346-014-0526-5.

Alonso, E., Pinyol, N. \& Puzrin, A. (2010). Geomechanics of failures. Advanced topics. Dordrecht, the Netherlands: Springer.

Alonso, E. E., Pinyol, N. M. \& Yerro, A. (2014). Mathematical modelling of slopes. Procedia Earth Planetary Sci. 9, 64-73.

Andersen, S. \& Andersen, L. (2010). Modelling of landslides with the material-point method. Comput. Geosci. 14, No. 1, 137-147.

Bardenhagen, S. G. \& Kober, E. M. (2004). The generalized interpolation material point method. Comput. Modeling Engng and Sci. 5, No. 6, 477-495.

Bishop, A. W. (1967). Progressive failure-with special reference to the mechanism causing it. Proceedings of the geotechnical conference, Olso, Norway, vol. 2, pp. 142-150.

Bishop, A. W. (1971). The influence of progressive failure on the choice of the method of stability analysis. Géotechnique 21, No. 2, 168-172, http://dx.doi.org/10.1680/geot.1971.21.2.168.

Bjerrum, L (1967). Progressive failure in slopes of overconsolidated plastic clay and clay- shales. J. Soil. Mech. Found. Div. Am. Soc. Civ. Engng 93, No. SM5, 3-49.

Bowden, F. \& Tabor, D. (1964). The friction and lubrication of solids. New York, NY, USA: Oxford University Press.

Campbell, C. S., Cleary, P. W. \& Hopkins, M. A. (1995). Large-scale landslide simulations: global deformation, velocities, and basal friction. J. Geophys. Res.: Solid Earth 100, No. B5, 8267-8283.
Cascini, L., Cuomo, S., Pastor, M. \& Sorbino, G. (2010). Modeling of rainfall-induced shallow landslides of the flow-type. J. Geotech. Geoenviron. Engng 1, No. 1, 85-98.

Cecinato, F. \& Zervos, A. (2012). Influence of thermomechanics in the catastrophic collapse of planar landslides. Can. Geotech. J. 49, No. 2, 207-225.

Cecinato, F., Zervos, A. \& Veveakis, E. (2011). A thermomechanical model for the catastrophic collapse of large landslides. Int. J. Numer. Analyt. Methods Geomech. 35, No. 14, $1507-1535$.

Chamot, P. (1993). El deslizamiento La Josefina en el Valle del Río Paute, Cuenca, Ecuador, report to the United Nations. Zurich, Switzerland: Swiss Relief Agencies (in Spanish).

Chen, T. C., Lin, M. L. \& Hung, J. J. (2003). Pseudostatic analysis of Tsao-Ling rockslide caused by Chi-Chi earthquake. Engng Geol. 71, No. 1-2, 31-47.

Cleary, P. W. \& Campbell, C. S. (1993). Self-lubrication for long runout landslides: examination by computer simulation. J. Geophys. Res. 98, No. 12B, 21911-21924.

Conte, E., Silvestri, F. \& Troncone, A. (2010). Stability analysis of slopes in soils with strain-softening behaviour. Comput. Geotech. 37, No. 5, 710-722.

Cooper, M. (1996). The progressive development of a failure slip surface in over-consolidated clay at Selborne, UK. Proceedings of the 7th international symposium on landslides, Trondheim, Norway (ed. K. Senneset), pp. 683-688. Rotterdam, the Netherlands: Balkema.

Cooper, M. R., Bromhead, E. N., Petley, D. J. \& Grant, D. I. (1998). The Selbourne cutting stability experiment. Géotechnique $\mathbf{4 8}$, No. 1, 83-101, http://dx.doi.org/10.1680/geot.1998.48.1.83.

Dai, F. C., Deng, J. H., Tham, L. G., Law, K. T. \& Lee, C. F. (2004). A large landslide in Zigui County, Three Gorges area. Can. Geotech. J. 41, No. 6, 1233-1240.

Darve, F. \& Laouafa, F. (2000). Instabilities in granular materials and application to landslides. Mech. Cohesive-Frictional Mater. 5, No. 8, 627-652.

Davis, R. O., Desai, C. S. \& Smith, N. R. (1993). Stabiltiy of motions of translatinoal landslide. J. Geotech. Engng 119, No. 3, $420-432$.

Di Toro, G., Hirose, T., Nielsen, S., Pennacchioni, G. \& Shimamoto, T. (2006). Natural and experimental evidence of melt lubrication of faults during earthquakes. Science 311, No. 5761, 647-649.

Dieterich, J. (1979). Modeling of rock friction 1. Experimental results and constitutive equations. J. Geophys. Res. 84, No. 5B, 2161-2168.

Dounias, G. T., Potts, D. M. \& Vaughan, P. R. (1996). Analysis of progressive failure and cracking in old British dams. Géotechnique 46, No. 4, 621-640, http://dx.doi.org/10.1680/ geot.1996.46.4.621.

Dowell, M. \& Jarratt, P. (1972). The 'Pegasus' method for computing the root of an equation. BIT 12, No. 4, 503-508.

Duncan, J. (1996). State of the art: limit equilibrium and finiteelement analysis of slopes. J. Geotech. Engng 122, No. 7 , 577-596.

Ferri, F., Di Toro, G., Hirose, T. \& Shimamoto, T. (2010). Evidence of thermal pressurization in high-velocity friction experiments on smectite-rich gouges. Terra Nova 22, No. 5, 347-353.

Follacci, J. P., Rochet, L. \& Serratrice, J. F. (1993). Glissement de La Clapière, St. Etienne de Tinée, Synthèse des connaissances et actualisation des risques, rapp. 92/PP/UN/I/DRM/03/AI/01. France: Nice: Centre Etude Techniques de l'Equipment.

Gens, A. \& Alonso, E. E. (2006). Aznalcóllar dam failure. Part 2: Stability conditions and failure mechanism. Géotechnique 56, No. 3, 185-201, http://dx.doi.org/10.1680/ geot.2006.56.3.203.

Goguel, J. (1978). Scale-dependent rockslide mechanisms, with emphasis on the role of pore fluid vaporization. In Rockslides and avalanches (ed. B. Voight), pp. 693-706. Amsterdam, the Netherlands: Elsevier.

Goren, L. \& Aharonov, E. (2007). Long runout landslides: The role of frictional heating and hydraulic diffusivity. Geophys. Res. Lett. 34, No. L07301, 1-7.

Goren, L. \& Aharonov, E. (2009). On the stability of landslides: a thermo-poro-elastic approach. Earth Planetary Sci. Lett. 277, No. 3-4, 365-372. 
Goren, L., Aharonov, E. \& Anders, M. H. (2010). The long runout of the Heart Mountain landslide: Heating, pressurization, and carbonate decomposition. J. Geophys. Res.: Solid Earth 115, No. 10B, 1-15.

Habib, P. (1967). Sur un mode de glissement des massifs rocheux. C. R. Acad. Sc. Paris 264, Serie A, 151-153 (in French).

Habib, P. (1975). Production of gaseous pore pressure during rock slides. Rock Mech. Rock Engng 7, No. 4, 193-197.

Han, R. \& Hirose, T. (2012). Clay-clast aggregates in fault gouge: an unequivocal indicator of seismic faulting at shallow depths? J. Structl Geol. 43, 92-99.

Harden, C. P. (2004). The 1993 Landslide dam at La Josefina in Southern Ecuador: a review of 'Sin plazo para La Esperanza'. Engng Geol. 74, No. 1-2, 157-161.

He, S. M., Liu, W. \& Wang, J. (2015). Dynamic simulation of landslide based on thermo-poro-elastic approach. Comput. Geosci. 75, 24-32.

Helmstetter, A., Sornette, D., Grasso, J. R., Andersen, J. V., Gluzman, S. \& Pisarenko, V. (2003). Slider-block friction model for landslides: application to Vajont and La Clapière landslides. J. Geophys. Res. 109, No. B2, http://dx.doi.org/10. 1029/2002JB002160.

Hendron, A. J \& Patton, F. D. (1985). The Vaiont slide, a geotechnical analysis based on new geologic observations of the failure surface, Technical Report GL-85-5. Washington, DC, USA: Department of the US Army Corps of Engineers.

Hewitt, K., Clague, J. J. \& Orwin, J. F. (2008). Legacies of catastrophic rock slope failures in mountain landscapes. Earth-Sci. Rev. 87, No. 1-2, 1-38.

HSL (HSL Mathematical Software Library) (2015). A collection of Fortran codes for large scale scientific computation. Harwell, Didcot, Oxfordshire, UK: STFC Rutherford Applieton Laboratory. See http://www.hsl.rl.ac.uk/ (accessed 29/07/2015).

Hungr, O., Leroueil, S. \& Picarelli, L. (2014). The Varnes classification of landslide types, an update. Landslides 11, No. 2, 167-194.

ICOLD (International Commission on Large Dams) (2002). Reservoir landslides: investigation and management - guidelines and case histories, Bulletin 124. Paris, France: International Commission on Large Dams.

IUGS (International Union of Geological Sciences)/International Working Group on Landslides (1995). A suggested method for describing the rate of movement of a landslide. Bull. Int. Assoc. Engng Geol. 52, 75-78.

Iverson, R. M., Reid, M. E. \& Lahusen, R. G. (1997). Debris-flow mobilization from landslides. Ann. Rev. Earth Planet Sci. 25, $85-138$.

Leroueil, S. (2001). Natural slopes and cuts: movement and failure mechanisms. Géotechnique 51, No. 3, 197-243, http://dx.doi.org/ 10.1680/geot.2001.51.3.197.

Liao, C. J., Lee, D. H., Wu, J. H. \& Lai, C. Z. (2011). A new ring-shear device for testing rocks under high normal stress and dynamic conditions. Engng Geol. 122, No. 1-2, 93-105.

Mesri, G. \& Shahien, M. (2003). Residual shear strength mobilized in first-time slope failures. J. Geotech. Geoenviron. Engng 129, No. 1, 12-31.

Mitchell, J. K. (1976). Fundamentals of soil behaviour. New York, NY, USA: John Wiley \& Sons.

Mizoguchi, K., Hirose, T., Shimamoto, T. \& Fukuyama, E. (2007). Reconstruction of seismic faulting by high-velocity friction experiments: An example of the 1995 Kobe earthquake. Geophys. Res. Lett. 34, No. 1, 2-4.

Müller, L. (1964). The rock slide in the Vajont Valley. Rock Mech. Engng Geol. 2, No. 3-4, 148-212.

Nonveiller, E. (1987). The Vajont reservoir slope failure. Engng Geol. 24, No. 1-4, 493-512.

Paronuzzi, P., Rigo, E. \& Bolla, A. (2013). Influence of fillingdrawdown cycles of the Vajont reservoir on Mt. Toc slope stability. Geomorphology 191, No. 1-2, 75-93.

Pastor, M., Blanc, T., Haddad, B., Drempetic, V., Morles, M. S., Dutto, P., Stickle, M. M., Mira, P. \& Merodo, J. A. (2014). Depth averaged models for fast landslide propagation: mathematical, rheological and numerical aspects. Archs Comput. Methods Engng 22, No. 1, 67-104.

Pinyol, N. M. \& Alonso, E. E. (2010a). Criteria for rapid sliding II. Engng Geol. 114, No. 3-4, 211-227.
Pinyol, N. M. \& Alonso, E. E. (2010b). Fast planar slides. A closed-form thermo-hydro-mechanical solution. Int. J. Numer. Analyt. Methods Geomech. 34, No. 1, 27-52.

Pinyol, N. M., Alonso, E. E., Corominas, J. \& Moya, J. (2011). Canelles landslide: modelling rapid drawdown and fast potential sliding. Landslides 9, No. 1, 33-51.

Plaza-Netos, G. \& Zevallos, O. (1994). The La Josefina rockslide. In the 1993 La Josefina rockslide and Río Paute landslide dam. Ecuador. Landslides News 8, 4-6.

Potts, D. M., Dounias, G. T. \& Vaughan, P. R. (1990). Finite element analysis of progressive failure of Carsington embankment. Géotechnique 40, No. 1, 79-101, http://dx.doi.org/10.1680/ geot.1990.40.1.79.

Rice, J. R. (2001). New perspectives in crack and fault dynamics. Mechanics for a New Millennium. Proceedings of the 20th international congress of theoretical and applied mechanics (eds H. Aref and J. W. Phillips), pp. 1-23. Chicago, IL, USA: Kluwer Academic Publishers.

Rice, J. R., Lapusta, N. \& Ranjith, K. (2001). Rate and state dependent friction and the stability of sliding between elastically deformable solids. J. Mech. Phys. Solids 49, No. 9, 1865-1898.

Ruina, A. (1983). Slip instability and state variable friction laws. J. Geophys. Res. 8, No. B12, 10359-10370.

Saito, M (1965). Forecasting the time of occurrence of a slope failure. Proceedings of the 6th international conference on soil mechanics and foundation engineering, Montreal, Canada, vol. 2, pp. 315-318.

Saito, M. (1969). Forecasting time of slope failure by tertiary creep. Proceedings of the 7 th international conference on soil mechanics and foundation engineering, Mexico City, Mexico, vol. 2, pp. 677-683.

Schuster, R. L., Salcedo, D. A. \& Valenzuela, L. (2002). Overview of catastrophic landslides of South America in the twentieth century. In Catastrophic landslides: effects, occurrences and mechanism (eds S. G. Evans and J. V. DeGraff). Boulder, CO, USA: Geological Society of America.

Semenza, E. (2001). La storia del Vaiont raccontata del geologo che ha scoperto la frana, Tecomproject. Ferrara, Italy: Editore Multimediale (in Italian).

Skeel, R. D. (1986). Construction of variable-stepsize multistep formulas. Math. Comput. 47, No. 176, 503-510.

Skempton, A. W. (1985). Residual strength of clays in landslides, folded strata, and the laboratory. Géotechnique 35, No. 1, 3-18, http://dx.doi.org/10.1680/geot.1985.35.1.3.

Skempton, A. W., Petley, F. R. S. \& Petley, D. J. (1967). The strength along structural discontinuities in stiff clays. Proceedings of geotechnical conference, Oslo, Norway, vol. 2, pp. $55-69$.

Sosio, R., Crosta, G. B. \& Hungr, O. (2008). Complete dynamic modeling calibration for the Thurwieser rock avalanche (Italian Central Alps). Engng Geol. 100, No. 1-2, 11-26.

Tang, C. L., Hu, J. C., Lin, M. L., Angelier, J., Lu, C. Y., Chan, Y. C. \& Chu, H. T. (2009). The Tsaoling landslide triggered by the Chi-Chi earthquake, Taiwan: Insights from a discrete element simulation. Engng Geol. 106, No. 1-2, 1-19.

Tika, T. E., Vaughan, P. R. \& Lemos, L. (1996). Fast shearing of pre-existing shear zones in soil. Géotechnique 46, No. 2, 197-233, http://dx.doi.org/10.1680/geot.1996.46.2.197.

Ujiie, K. \& Tsutsumi, A. (2010). High-velocity frictional properties of clay-rich fault gouge in a megasplay fault zone, Nankai subduction zone. Geophys. Res. Lett. 37, No. 24, 1-5.

Uriel Romero, S. \& Molina, R. (1977). Kinematic aspects of Vaiont slide. Proceedings of the 3rd international conference of the ISRMR, pp. 865-870. Denver, CO, USA: National Academy of Sciences $2 \mathrm{~B}$.

Vardoulakis, I. (2000). Catastrophic landslides due to frictional heating of the failure plane. Mech. Cohesive-frictional Mater. 5, No. 6, 443-467.

Vardoulakis, I. (2002). Dynamic thermo-poro-mechanical analysis of catastrofic landslides. Géotechnique 52, No. 3, 157-171, http:// dx.doi.org/10.1680/geot.2002.52.3.157.

Veveakis, E., Vardoulakis, I. \& Di Toro, G. (2007). Thermoporomechanics of creeping landslides: The 1963 Vaiont slide, northern Italy. J. Geophys. Res. 112, No. F3, F03026. 
Voight, B. (1978). Rockslides and avalanches, vol. 1. New York, NY, USA: Elsevier.

Voight, B. \& Faust, C. (1982). Frictional heat and strength loss in some rapid landslides. Géotechnique 32, No. 1, 43-54, http://dx. doi.org/10.1680/geot.1982.32.1.43.

Wagner, W. \& Kruse, A. (1998). Properties of water and steam. Berlin, Germany: Springer-Verlag.

Wang, F. W., Zhang, Y. M., Huo, A. T., Matsumoto, T. \& Huang, B. T. (2004). The July 14, 2003 Qianjiangping landslide, Three Gorges Reservoir, China. Landslides 1, No. 2, 157-162.

Wedage, A., Morgenstern, N. R. \& Chan, D. H. (1998). A strain rate dependent constitutive model for clays at residual strength. Can. Geotech. J. 35, No. 2, 364-373.

Więckowski, Z., Sung-Kie, Y. \& Jeoung-Heum, Y. (1999). A particle-in-cell solution to the silo discharging problem. Int. J. Numer. Analyt. Methods Geomech. 45, No. 9, 1203-1225.
Wu, J. H. \& Chen, C. H. (2011). Application of DDA to simulate characteristics of the Tsaoling landslide. Comput. Geotech. 38, No. 5, 741-750.

Yang, C. M., Yu, W. L., Dong, J. J., Kuo, C. Y., Shimamoto, T., Lee, C. T., Togo, T. \& Miyamoto, Y. (2014). Initiation, movement, and run-out of the giant Tsaoling landslide - What can we learn from a simple rigid block model and a velocity-displacement dependent friction law? Engng Geol. 182, Part B, 158-181.

Yerro, A., Alonso, E. E. \& Pinyol, N. M. (2014). Modelling progressive failure with MPM. In Numerical methods in geotechnical engineering, Proceedings of NUMGE 2014, Delft (eds M. Hicks, R. B. J. Brinkgreve and A. Rohe), vol. 1, pp. 319-323. Leiden, The Netherlands: Balkema.

Zabala, F. \& Alonso, E. E. (2011). Progressive failure of Aznalcóllar dam using the material point method. Géotechnique 61, No. 9, 795-808, http://dx.doi.org/10.1680/geot.9.P.134. 